$$
\begin{array}{r}
\text { Pontifícia Universidade Católica } \\
\text { do Rio de Janeiro }
\end{array}
$$

Cláudio Costa do Nascimento

\title{
Um Modelo de ALM para Fundos de Pensão Usando Programação Estocástica Mista-Inteira
}

\section{Dissertação de Mestrado}

\begin{abstract}
Dissertação apresentada ao Programa de Pós-Graduação em Engenharia Elétrica da PUC-Rio como requisito parcial para obtenção do título de Mestre em Engenharia Elétrica.
\end{abstract}

Orientador: Prof. Álvaro de Lima Veiga Filho

Rio de Janeiro

Setembro de 2012 


$$
\begin{array}{r}
\text { Pontifícia Universidade Católica } \\
\text { do Rio de Janeiro }
\end{array}
$$

Cláudio Costa do Nascimento

\title{
Um Modelo de ALM para Fundos de Pensão Usando Programação Estocástica Mista-Inteira
}

\begin{abstract}
Dissertação apresentada como requisito parcial para obtenção do grau de Mestre pelo Programa de Pós-Graduação em Engenharia Elétrica do Departamento de Engenharia Elétrica do Centro Técnico Científico da PUC-Rio. Aprovada pela Comissão Examinadora abaixo assinada.
\end{abstract}

\author{
Prof. Álvaro de Lima Veiga Filho \\ Orientador \\ Departamento de Engenharia Elétrica - PUC-Rio
}

Prof. Luiz Felipe Jacques da Motta Departamento de Administração-PUC-Rio

Prof. Roberto Westenberger

UFRJ

Prof. José Eugenio Leal Coordenador Setorial do Centro

Técnico Científico

Rio de Janeiro, 21 de setembro de 2012 


\section{Resumo}

do Nascimento, Cláudio Costa; Veiga Filho, Álvaro de Lima (Orientador). Um Modelo de ALM para Fundos de Pensão Usando Programação Estocástica Mista-Inteira. Rio de Janeiro, 2012. 84p. Dissertação de Mestrado - Departamento de Engenharia Elétrica, Pontifícia Universidade Católica do Rio de Janeiro.

Nesta dissertação será apresentado como fundos de pensão na modalidade benefícios definidos podem recorrer à programação linear inteira mista para resolver problemas de ALM. Devemos considerar que a legislação brasileira determina que participantes e patrocinadores devam pagar contribuição extraordinária em caso de déficit ou, em caso de superávit persistente, parte do excesso contributivo deve ser devolvido aos participantes. Esse aspecto legal particular requer o uso de técnicas de programação inteira. Com o objetivo de modelar a ocorrência de eventos de desequilíbrio nos fundos de pensão foi necessária a introdução de variáveis inteiras para proceder a contagem do número de ocorrências desses eventos. Um exemplo simples, porém realista, foi introduzido para mostrar como os gestores de um fundo de pensão não só determinam a menor contribuição necessária à operação do fundo de pensão, mas também devem investir os recursos garantidores a fim de assegurar essa contribuição mínima.

\section{Palavras-Chave}

ALM; fundo de pensão; programação linear estocástica mista inteira. 


\section{Abstract}

do Nascimento, Cláudio Costa; Veiga Filho, Álvaro de Lima (Advisor).

An Stochastic Model for Pension fund Using Linear Programming Integer Mixed. Rio de Janeiro, 2012. 84p. Dissertação de Mestrado Departamento de Engenharia Elétrica, Pontifícia Universidade Católica do Rio de Janeiro.

In this dissertation we discuss how defined benefit plans can use mixed integer linear programming to solve an ALM problem. We must consider that Brazilian pension fund regulations commands that participants and sponsors alike are to pay an extra contribution in case of deficit, or, in case of a persistent superavit, part of the exceeding contribution should return to its participants. This particular legal aspect forces us to use integer programming techniques. In order to model this lack of balance, an integer variable was considered so as to count how many times it occurs. A simple but realistic example is presented to show how pension fund managers may not only plan their operation to get the minimal possible contribution but also invest money to support it.

\section{Keywords}

ALM; pension fund; stochastic linear programming integer mixed. 
Todos os direitos reservados. É proibida a reprodução total ou parcial do trabalho sem autorização da universidade, do autor e do orientador.

\section{Cláudio Costa do Nascimento}

Graduou-se em Física pela Universidade Federal do Rio de Janeiro em 1977. Tornou-se Mestre em Engenharia Biomédica pela COPPE, UFRJ, em 1978. Graduou-se em Estatística na Escola Nacional de Ciências Estatísticas (ENCE) em 1984. Participou de diversos congressos de Estatística e Finanças. Ingressou na Fundação de Previdência e Assistência Social do BNDES - FAPES em 1985 como gerente, sendo indicado, em 2002, a chefe do Departamento de Investimentos. Em 2007 passou a titular da Assessoria de Assuntos Estratégicos, cargo que exerce até hoje. Em 2003, tornou-se Mestre em Métodos Matemáticos em Finanças pelo Instituto de Matemática Pura e Aplicada (IMPA).

Ficha Catalográfica

Nascimento, Cláudio Costa do

Um modelo da ALM para fundos de pensão usando programação estocástica mista-inteira / Cláudio Costa do Nascimento ; orientador: Álvaro de Lima Veiga Filho. - 2012.

$84 \mathrm{f} . ; 30 \mathrm{~cm}$

Dissertação (mestrado) - Pontifícia Universidade Católica do Rio de Janeiro, Departamento de Engenharia Elétrica, 2012.

\section{Inclui bibliografia}

1. Engenharia elétrica - Teses. 2. ALM. 3. Plano de benefícios definido. 4. Otimização linear estocástica inteira mista. I. Veiga Filho, Álvaro de Lima. II. Pontifícia Universidade Católica do Rio de Janeiro. Departamento de Engenharia Elétrica. III. Título. 


\section{Agradecimentos}

Aos meus pais, Carlos Alberto de Nascimento e Cacilda Costa do Nascimento (in memoriam), que me ensinaram os princípios e valores em que todos devemos pautar nossas vidas, agradeço os sacrifícios que lhes foram impostos para que eu pudesse trilhar o caminho dos estudos e o particular gosto pelas ciências matemáticas. Em especial, gostaria de agradecer à minha companheira, Nádia Milagres, pela paciência e dedicação e por ter me ajudado a suportar e superar todas as dúvidas quando nem tudo acontecia conforme desejado.

Sou grato também aos meus professores, que aqui homenageio na figura da professora Sônia Fonseca - um mito na ENCE que, além de me ensinar as primeiras lições de teoria de probabilidades, me ensinou também os princípios e fundamentos da previdência privada no Brasil e no mundo quando me convidou para trabalhar na FAPES, empresa que ensejou esta dissertação. Agradeço ainda aos meus superiores hierárquicos, representados pelo Dr. Sebastião Martins Soares - verdadeiro modelo de sabedoria e percepção no que diz respeito ao que é verdadeiramente relevante. A ele devo a seguinte lição: ainda que se percam algumas batalhas, nossas crenças e convicções permitirão o triunfo e a prazerosa sensação de que vencem as boas ideias e a capacidade de apresentá-las com clareza, paciência e serenidade.

Agradeço ao meu orientador, o professor Álvaro Veiga, que, com seu sólido conhecimento dos problemas de ALM, ajudou a conduzir o presente trabalho por um caminho que levasse à inovação metodológica ao mesmo tempo em que permitisse a sua conclusão com todo o rigor exigido, sem excessos desnecessários, respeitando os limites de uma dissertação de mestrado. Sou grato ao professor Luciano Vereda, pelas discussões que tivemos sobre a real utilidade de modelos de ALM no Brasil. Esses embates permitiram reforçar a crença de que eles não só são úteis como também necessários para a boa gestão de um fundo de pensão. Agradeço também ao professor Cristiano Fernandes, que me permitiu cursar disciplinas como aluno especial para, posteriormente ingressar em definitivo no curso de mestrado. Sem suas recomendações, este trabalho não teria sido nem iniciado. Agradeço aos professores Roberto Westenberger e Luiz Felipe Jacques da Motta pelos excelentes e oportunos comentários e por sua participação na minha banca de dissertação. Esses dois nomes sem dúvida agregam inestimável valor ao trabalho apresentado. Agradeço também, e de forma muito especial, ao Davi Michel Valladão pela paciência que teve em adaptar, para uma plataforma computacional mais adequada aos propósitos do trabalho, o código até então elaborado.

Agradeço ainda à Ana Luiza pela dedicação na revisão ortográfica e gramatical e por ter transformado o trabalho original em uma nova versão mais fácil e agradável à leitura, essencialmente livre de erros de português. Confesso que jamais conseguiria fazer esse trabalho. Agradeço também à Marcia, que teve a paciência de reformatar todo o trabalho para que ficasse de acordo com as normas estabelecidas pela PUC- Rio. 


\section{Sumário}

$\begin{array}{ll}\text { 1. Introdução } & 10\end{array}$

$\begin{array}{lr}\text { 2. Revisão bibliográfica } & 17\end{array}$

3. A descrição do problema

3.1. Alguns conceitos importantes 26

3.2. O modelo matemático 33

3.2.1. Contribuição normal 38

3.2.2. Contribuição extraordinária 41

3.2.3. Devolução de contribuição $\quad 46$

3.2.4. A função objetivo do problema de minimização 48

3.2.5. O conjunto de restrições

4. Geração dos cenários

4.1. Os ativos financeiros $\quad 58$

4.2. Os benefícios, a massa salarial e o passivo atuarial 63

5. Estudo de caso $\quad \mathbf{6 5}$

5.1. Primeiro exemplo: Necessidade de contribuição extraordinária 66

5.2. Segundo exemplo: Devolução de contribuição 72

$\begin{array}{lr}\text { 6. Conclusões } & 81\end{array}$

7. Referências bibliográficas $\quad 83$ 


\section{Lista de figuras}

Figura 1: Dinâmica do processo de decisão 27

Figura 2: Estrutura em árvore - enumeração dos cenários 30

Figura 3: Representação dos fluxos de caixa levando em conta o cenário $29 \quad 71$

Figura 4: Representação dos fluxos de caixa levando em conta o cenário $\quad 78$ 


\section{Lista de tabelas}

Tabela 5.1: Valores ótimos obtidos considerando o cenário 29

Tabela 5.2: Retorno dos ativos - cenário 29 expresso em \% ao ano 68

Tabela 5.3: Compras e vendas de ativos - cenário 29 expresso em milhões de Reais

Tabela 5.4: Total investido - cenário 29 expresso em \% ao ano 70

Tabela 5.5: Perfil dos investimentos - cenário 29 expresso em \% 71

Tabela 5.6: Valores ótimos obtidos considerando o cenário 3

Tabela 5.7: Retorno dos ativos - cenário 3 expresso em \% ao ano 75

Tabela 5.8: Compras e vendas de ativos - cenário 3 expresso em milhões de Reais 76

Tabela 5.9: Fontes e usos de recursos - cenário 3 expressos em milhões de Reais

Tabela 5.10: Demonstrativo de fluxo de caixa - cenário 3 expressos em milhões de Reais

Tabela 5.11: Total investido - cenário 3 expresso em milhões de Reais

Tabela 5.12: Perfil dos investimentos - cenário 3 expresso em \% 


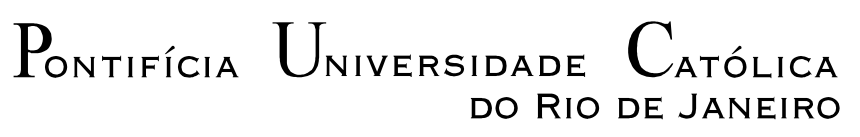

Cláudio Costa do Nascimento

\title{
Um Modelo de ALM para Fundos de Pensão Usando Programação Estocástica Mista-Inteira
}

Dissertação apresentada como requisito parcial para obtenção do grau de Mestre pelo Programa de Pós-Graduação em Engenharia Elétrica do Departamento de Engenharia Elétrica do Centro Técnico Científico da PUC-Rio. Aprovada pela Comissão Examinadora abaixo assinada.

\author{
Prof. Álvaro de Lima Veiga Filho \\ Orientador \\ Departamento de Engenharia Elétrica - PUC-Rio
}

Prof. Luiz Felipe Jacques da Motta Departamento de Administração-PUC-Rio

Prof. Roberto Westenberger

UFRJ

Prof. José Eugenio Leal

Coordenador Setorial do Centro

Técnico Científico

Rio de Janeiro, 21 de setembro de 2012 
Todos os direitos reservados. É proibida a reprodução total ou parcial do trabalho sem autorização da universidade, do autor e do orientador.

\section{Cláudio Costa do Nascimento}

Graduou-se em Física pela Universidade Federal do Rio de Janeiro em 1977. Tornou-se Mestre em Engenharia Biomédica pela COPPE, UFRJ, em 1978. Graduou-se em Estatística na Escola Nacional de Ciências Estatísticas (ENCE) em 1984. Participou de diversos congressos de Estatística e Finanças. Ingressou na Fundação de Previdência e Assistência Social do BNDES - FAPES em 1985 como gerente, sendo indicado, em 2002, a chefe do Departamento de Investimentos. Em 2007 passou a titular da Assessoria de Assuntos Estratégicos, cargo que exerce até hoje. Em 2003, tornou-se Mestre em Métodos Matemáticos em Finanças pelo Instituto de Matemática Pura e Aplicada (IMPA).

Ficha Catalográfica

Nascimento, Cláudio Costa do

Um modelo da ALM para fundos de pensão usando programação estocástica mista-inteira / Cláudio Costa do Nascimento ; orientador: Álvaro de Lima Veiga Filho. - 2012.

84 f. ; $30 \mathrm{~cm}$

Dissertação (mestrado) - Pontifícia Universidade Católica do Rio de Janeiro, Departamento de Engenharia Elétrica, 2012.

Inclui bibliografia

1. Engenharia elétrica - Teses. 2. ALM. 3. Plano de benefícios definido. 4. Otimização linear estocástica mista inteira. I. Veiga Filho, Álvaro de Lima. II. Pontifícia Universidade Católica do Rio de Janeiro. Departamento de Engenharia Elétrica. III. Título.

CDD: 621.3 


\section{Agradecimentos}

Aos meus pais, Carlos Alberto de Nascimento e Cacilda Costa do Nascimento (in memoriam), que me ensinaram os princípios e valores em que todos devemos pautar nossas vidas, agradeço os sacrifícios que lhes foram impostos para que eu pudesse trilhar o caminho dos estudos e o particular gosto pelas ciências matemáticas. Em especial, gostaria de agradecer à minha companheira, Nádia Milagres, pela paciência e dedicação e por ter me ajudado a suportar e superar todas as dúvidas quando nem tudo acontecia conforme desejado.

Sou grato também aos meus professores, que aqui homenageio na figura da professora Sônia Fonseca - um mito na ENCE que, além de me ensinar as primeiras lições de teoria de probabilidades, me ensinou também os princípios e fundamentos da previdência privada no Brasil e no mundo quando me convidou para trabalhar na FAPES, empresa que ensejou esta dissertação. Agradeço ainda aos meus superiores hierárquicos, representados pelo Dr. Sebastião Martins Soares - verdadeiro modelo de sabedoria e percepção no que diz respeito ao que é verdadeiramente relevante. A ele devo a seguinte lição: ainda que se percam algumas batalhas, nossas crenças e convicções permitirão o triunfo e a prazerosa sensação de que vencem as boas ideias e a capacidade de apresentá-las com clareza, paciência e serenidade.

Agradeço ao meu orientador, o professor Álvaro Veiga, que, com seu sólido conhecimento dos problemas de ALM, ajudou a conduzir o presente trabalho por um caminho que levasse à inovação metodológica ao mesmo tempo em que permitisse a sua conclusão com todo o rigor exigido, sem excessos desnecessários, respeitando os limites de uma dissertação de mestrado. Sou grato ao professor Luciano Vereda, pelas discussões que tivemos sobre a real utilidade de modelos de ALM no Brasil. Esses embates permitiram reforçar a crença de que eles não só são úteis como também necessários para a boa gestão de um fundo de pensão. Agradeço também ao professor Cristiano Fernandes, que me permitiu cursar disciplinas como aluno especial para, posteriormente ingressar em definitivo no curso de mestrado. Sem suas recomendações, este trabalho não teria sido nem iniciado. Agradeço aos professores Roberto Westenberger e Luiz Felipe Jacques da Motta pelos excelentes e oportunos comentários e por sua participação na minha banca de dissertação. Esses dois nomes sem dúvida agregam inestimável valor ao trabalho apresentado. Agradeço também, e de forma muito especial, ao Davi Michel Valladão pela paciência que teve em adaptar, para uma plataforma computacional mais adequada aos propósitos do trabalho, o código até então elaborado.

Agradeço ainda à Ana Luiza pela dedicação na revisão ortográfica e gramatical e por ter transformado o trabalho original em uma nova versão mais fácil e agradável à leitura, essencialmente livre de erros de português. Confesso que jamais conseguiria fazer esse trabalho. Agradeço também à Marcia, que teve a paciência de reformatar todo o trabalho para que ficasse de acordo com as normas estabelecidas pela PUC-Rio. 


\section{Resumo}

do Nascimento, Cláudio Costa; Veiga Filho, Álvaro de Lima (Orientador). Um Modelo de ALM para Fundos de Pensão Usando Programação Estocástica Mista-Inteira. Rio de Janeiro, 2012. 84p. Dissertação de Mestrado - Departamento de Engenharia Elétrica, Pontifícia Universidade Católica do Rio de Janeiro.

Nesta dissertação será apresentado como fundos de pensão na modalidade benefícios definidos podem recorrer à programação linear inteira mista para resolver problemas de ALM. Devemos considerar que a legislação brasileira determina que participantes e patrocinadores devam pagar contribuição extraordinária em caso de déficit ou, em caso de superávit persistente, parte do excesso contributivo deve ser devolvido aos participantes. Esse aspecto legal particular requer o uso de técnicas de programação inteira. Com o objetivo de modelar a ocorrência de eventos de desequilíbrio nos fundos de pensão foi necessária a introdução de variáveis inteiras para proceder a contagem do número de ocorrências desses eventos. Um exemplo simples, porém realista, foi introduzido para mostrar como os gestores de um fundo de pensão não só determinam a menor contribuição necessária à operação do fundo de pensão, mas também devem investir os recursos garantidores a fim de assegurar essa contribuição mínima.

\section{Palavras-Chave}

ALM; plano de benefícios definido; otimização linear estocástica mista inteira. 


\section{Abstract}

do Nascimento, Cláudio Costa; Veiga Filho, Álvaro de Lima (Advisor). An ALM model for defined benefit pension plan using stochastic mixed integer linear programming. Rio de Janeiro, 2012. 84p. Dissertação de Mestrado - Departamento de Engenharia Elétrica, Pontifícia Universidade Católica do Rio de Janeiro.

In this dissertation we discuss how defined benefit plans can use mixed integer linear programming to solve an ALM problem. We must consider that Brazilian pension fund regulations commands that participants and sponsors alike are to pay an extra contribution in case of deficit, or, in case of a persistent superavit, part of the exceeding contribution should return to its participants. This particular legal aspect forces us to use integer programming techniques. In order to model this lack of balance, an integer variable was considered so as to count how many times it occurs. A simple but realistic example is presented to show how pension fund managers may not only plan their operation to get the minimal possible contribution but also invest money to support it.

\section{Keywords}

ALM; defined benefit pension fund; stochastic mixed integer linear programming. 


\section{Sumário}

1. Introdução 10

2. Revisão bibliográfica 17

3. A descrição do problema

3.1. Alguns conceitos importantes 26

3.2. O modelo matemático 33

3.2.1. Contribuição normal $\quad 38$

3.2.2. Contribuição extraordinária 41

3.2.3. Devolução de contribuição 46

3.2.4. A função objetivo do problema de minimização 48

3.2.5. O conjunto de restrições

4. Geração dos cenários

4.1. Os ativos financeiros $\quad 58$

4.2. Os benefícios, a massa salarial e o passivo atuarial 63

5. Estudo de caso

5.1. Primeiro exemplo: Necessidade de contribuição extraordinária 66

5.2. Segundo exemplo: Devolução de contribuição 72

$\begin{array}{lr}\text { 6. Conclusões } & 81\end{array}$

7. Referências bibliográficas $\quad 83$ 


\section{Lista de figuras}

Figura 1: Dinâmica do processo de decisão 27

Figura 2: Estrutura em árvore - enumeração dos cenários 30

Figura 3: Representação dos fluxos de caixa levando em conta o cenário 2971

Figura 4: Representação dos fluxos de caixa levando em conta o cenário 378 


\section{Lista de tabelas}

Tabela 5.1: Valores ótimos obtidos considerando o cenário 29

Tabela 5.2: Retorno dos ativos - cenário 29 expresso em \% ao ano 68

Tabela 5.3: Compras e vendas de ativos - cenário 29 expresso em milhões de Reais

Tabela 5.4: Total investido - cenário 29 expresso em milhões de Reais $\quad 70$

Tabela 5.5: Perfil dos investimentos - cenário 29 expresso em \% 71

Tabela 5.6: Valores ótimos obtidos considerando o cenário 3

Tabela 5.7: Retorno dos ativos - cenário 3 expresso em \% ao ano 75

Tabela 5.8: Compras e vendas de ativos - cenário 3 expresso em milhões de Reais

Tabela 5.9: Fontes e usos de recursos - cenário 3 expressos em milhões de Reais

Tabela 5.10: Demonstrativo de fluxo de caixa - cenário 3 expressos em milhões de Reais

Tabela 5.11: Total investido - cenário 3 expresso em milhões de Reais

Tabela 5.12: Perfil dos investimentos - cenário 3 expresso em \% 


\section{Introdução}

O presente trabalho tem por objetivo apresentar uma metodologia de gerenciamento de um plano de benefício de caráter previdenciário na modalidade de benefício definido ${ }^{1}$, de modo a garantir que o provimento dos benefícios prometidos pelo plano seja permanentemente assegurado aos seus participantes.

Um fundo de pensão - empresa gestora de planos de benefício - “é uma fundação ou uma sociedade civil que gere o patrimônio de contribuições de participantes e patrocinadora com o objetivo de proporcionar rendas ou pecúlios". 2 Podemos, portanto, sugerir que a missão de um fundo de pensão é pagar aos participantes os benefícios que constam do contrato previdenciário celebrado entre eles e o fundo de pensão.

O primeiro ordenamento jurídico-legal aplicável aos fundos de pensão surgiu com a promulgação, em 15 de julho de 1977, da Lei 6.435. Conforme essa Lei, o Poder Público deve agir no sentido de preservar a liquidez e solvência dos planos de benefício.

Em 29 de maio de 2001 foram sancionadas as Lei Complementares 108 e 109. Essas duas leis representam um grande avanço em relação à Lei 6.435 e reafirmam que os valores a serem preservados pelos fundos de pensão são a liquidez, a solvência e o equilíbrio.

\footnotetext{
${ }^{1}$ As entidades de previdência complementar podem ser constituídas nas modalidades de benefício definido - BD; contribuição definida - CD; ou, ainda, de contribuição variável. As definições estão indicadas na Resolução CGPC n ${ }^{\circ} 16$, de 22 de novembro de 2000.

Art. $2^{\circ}$ Entende-se por plano de benefício de caráter previdenciário na modalidade de benefício definido aquele cujos benefícios programados têm seu valor ou nível previamente estabelecidos, sendo o custeio determinado atuarialmente, de forma a assegurar sua concessão e manutenção.

Art. $3^{\circ}$ Entende-se por plano de benefício de caráter previdenciário na modalidade de contribuição definida aquele cujos benefícios programados têm seu valor permanentemente ajustado ao saldo de conta mantido em favor do participante, inclusive na fase de percepção de benefícios, considerando o resultado líquido de sua aplicação, os valores aportados e os benefícios pagos.

Art. $4^{\circ}$ Entende-se por plano de benefício de caráter previdenciário na modalidade de contribuição variável aquele cujos benefícios programados apresentam a conjugação das características das modalidades de contribuição definida e benefício definido.
}

2 Origem: Wikipédia a enciclopédia livre. 
Apesar de citados na Lei Complementar 109, esses três termos não são definidos por ela. Assim sendo, neste trabalho serão consideradas as seguintes definições:

- Liquidez é um conceito financeiro que se refere à facilidade com que um ativo pode ser convertido no meio de troca da economia, ou seja, a facilidade com que pode ser convertido em dinheiro. $\mathrm{O}$ grau de agilidade de conversão de um investimento, sem perda significativa de seu valor, mede sua liquidez ${ }^{3}$. Em um fundo de pensão, esse conceito se traduz na sua capacidade de pagar os benefícios aos assistidos no valor e nas épocas acordados no contrato previdenciário.

- Solvência, "em finanças e contabilidade, é o estado do devedor que possui seu ativo maior do que o passivo, ou a sua capacidade de cumprir os compromissos com recursos que constituem seu patrimônio ou seu ativo. Portanto, do ponto de vista econômico, uma empresa é solvente quando está em condições de fazer frente a suas obrigações correntes e ainda apresentar uma situação patrimonial e uma expectativa de lucros que garantam sua sobrevivência no futuro"4.

- Equilíbrio refere-se à situação em que o valor do ativo é igual ao valor do passivo.

O gerenciamento ao qual nos referimos deve considerar a liquidez, a solvência e o equilíbrio do fundo de pensão conforme definido anteriormente. Isso nos remete ao conceito que passa a ser um dos mais importantes deste trabalho. $\mathrm{Na}$ verdade, o problema a ser resolvido é denominado problema de ALM. A Society of Actuaries - SOA [2] define ALM da seguinte maneira:

Definição 1.0.1 (Asset Liability Management - ALM) ALM é uma prática de gerenciamento de negócios na qual as decisões tomadas e ações praticadas com relação aos ativos e passivos são coordenadas. ALM pode ser definido como um processo contínuo de formulação, implementação, monitoramento e revisão de estratégias relacionadas aos ativos e passivos para atingir os objetivos financeiros da organização, considerando sua tolerância ao risco e outras restrições impostas. ALM não e só relevante, mas também crucial ao bom gerenciamento financeiro de qualquer

\footnotetext{
${ }^{3}$ Origem: Wikipédia a enciclopédia livre.

${ }^{4}$ Origem: Wikipédia a enciclopédia livre.
} 
organização que busque atingir suas necessidades futuras de fluxo de caixa e de exigências de capital. ${ }^{5}$

Deve-se observar na definição apresentada que o problema de $A L M$ não se restringe somente aos fundos de pensão. Na verdade, a definição nem os cita. Vamos, no entanto, identificar os pontos de contato entre a definição da SOA e o modelo de administração de um fundo de pensão.

Antes de compreender o que seja "decisão coordenada sobre ativos e passivos", devemos inicialmente caracterizar esses termos. Os ativos permitidos estão especificados na seção I do capítulo VI da Resolução CMN n ${ }^{0} 3.792$, de 24 de setembro de 2009. Após a leitura dessa Resolução não restam dúvidas sobre os ativos de interesse para os fundos de pensão. Quanto aos passivos, os atuários os dividem dois grupos: (i) a Reserva Matemática de Benefícios Concedidos, que especifica o valor, expresso em moeda corrente, dos compromissos do fundo de pensão para com os participantes que já alcançaram a condição de assistidos e (ii) a Reserva Matemática de Benefícios a Conceder, que especifica o valor, também expresso em moeda corrente, dos compromissos do fundo de pensão para com os participantes que ainda vão alcançar a condição de assistidos.

Agora podemos avançar no propósito de mostrar por que os fundos de pensão devem se apropriar do conceito de ALM. A Lei Complementar 109 explicita, como objetivos a serem perseguidos pelos fundos de pensão, a preservação da sua liquidez, solvência e equilíbrio. Essa busca pode ser interpretada como um dos objetivos financeiros do fundo de pensão, conforme recomendado na definição de ALM. Quanto à indicação de que "as decisões tomadas e ações praticadas com relação aos ativos e passivos" sejam "coordenadas", isso pode ser interpretado como uma recomendação ao gestor do fundo. Suas decisões de investimento devem estar alinhadas ao espírito da Lei: os proventos devidos aos assistidos devem ser pagos no valor e datas acertadas (liquidez e necessidades de fluxo de caixa); os ativos do fundos deverão ser, no mínimo, iguais ao seu passivo (equilíbrio); e, admitida a perenidade do fundo de pensão, o valor do ativo dos participantes e assistidos, em um futuro distante, deverá ser superior ao valor do seu passivo na mesma ocasião (solvência). Resta ainda traduzir os conceitos de "tolerância ao risco e outras restrições impostas"

\footnotetext{
${ }^{5}$ Tradução do autor.
} 
para a linguagem dos fundos de pensão. As restrições de alocação de ativos são aquelas indicadas na Resolução CMN n ${ }^{0}$ 3.792, de 24 de setembro de 2009. Além dessas imposições de caráter legal, o Conselho Deliberativo do fundo de pensão ${ }^{6}$ acrescenta outras condições que limitam a ação do gestor de investimentos. Em geral, essas condições apresentadas pelo Conselho Deliberativo são expressas pela proibição de o fundo de pensão transacionar algum ativo específico ou, ainda, de realizar operações consideradas de risco mais elevado. Por exemplo, é comum que fundos de pensão restrinjam transações com empresas que não tenham selo de responsabilidade social, que adquiram títulos privados com classificação de risco elevado e não operem com derivativos financeiros. Essas imposições também podem ser consideradas como providências que visam diminuir a exposição do fundo de pensão a riscos indesejáveis.

A medida de equilíbrio que poderia ser naturalmente adotada consiste em obter o valor da relação entre o ativo e o passivo do fundo de pensão em cada instante de decisão. Essa forma de caracterizar equilíbrio, apesar de sua praticidade e fácil utilização, é inadequada para a administração rotineira do fundo de pensão. Devemos ter em mente que tanto os ativos quanto os passivos são variáveis aleatórias e devem ser tratados como tais. Desse modo, uma atitude mais adequada é definir um intervalo no qual tal relação possa variar livremente, sem que seja exigida dos gestores qualquer ação corretiva. Essa abordagem encontra respaldo na Resolução CGPG ${ }^{0}$ 26, de 29 de setembro de $2008^{7}$. Ela determina que alguma ação deve ser posta em prática quando a razão entre ativo e passivo for superior a 1,25 por mais de três exercícios consecutivos. Neste trabalho, a determinação dessa condição especial vai exigir a inserção de uma variável capaz de contar a quantidade de vezes que certo evento ocorreu. Essa modelagem do problema, que consideramos a principal contribuição ao problema de ALM, é pouco comum entre os fundos de pensão brasileiros, contudo oferece ao gestor a possibilidade de antever a necessidade de cobrança de contribuição extraordinária

\footnotetext{
${ }^{6}$ Por determinação da Lei Complementar 108, de 29 de maio de 2001, os fundos de pensão devem constituir em sua estrutura organizacional um Conselho Deliberativo, órgão máximo da estrutura organizacional, responsável pela definição da política geral de administração da entidade e de seus planos de benefício.

${ }^{7}$ Essa Resolução dispõe sobre as condições e os procedimentos a serem observados pelas entidades fechadas de previdência complementar na apuração do resultado, na destinação e utilização de superávit, bem como no equacionamento de déficit dos planos de benefício de caráter previdenciário que administram.
} 
dos participantes e patrocinadores ou a devolução aos participantes de parte das contribuições cobradas em excesso. Mesmo cientes da dificuldade introduzida no problema pela inclusão de variáveis binárias, estamos convencidos de que essa forma de resolver o problema de ALM representa, na verdade, um modelo que se assemelha em muito ao modo de pensar do gestor do fundo de pensão.

Por fim, podemos dar sentido à sentença: “ALM pode ser definido como um processo contínuo de formulação, implementação, monitoramento e revisão de estratégias relacionadas aos ativos e passivos para atingir os objetivos financeiros da organização, considerando sua tolerância ao risco e outras restrições impostas". Isso nos remete à determinação da metodologia a ser empregada para a solução do problema de ALM. Embora a SOA não indique diretamente que as estratégias implementadas sejam ótimas sob algum aspecto, podemos acrescentar esse dado à sua definição do problema.

Com isso, vamos transformá-lo em um problema de otimização. Infelizmente, o termo otimização é tão amplo quanto vago. $\mathrm{O}$ que faremos na verdade é resolver o problema de ALM usando otimização linear. Seria uma total ingenuidade supor que o ambiente de decisão dos fundos de pensão seja habitado apenas por variáveis determinísticas. Recomendamos, então, que o problema de ALM seja resolvido admitindo que as decisões sejam tomadas sequencialmente sob incerteza. As incertezas serão introduzidas no problema através da construção de um conjunto de trajetórias ou cenários para a evolução futura das variáveis aleatórias, que serão organizadas em forma de árvore. Partindo de um ponto inicial, definido pelos valores atuais das variáveis aleatórias, as trajetórias se subdividem em instantes de tempo pré-definidos chamados estágios, dentro de um dado horizonte de planejamento, formando a chamada árvore de cenários. As decisões serão tomadas em cada nó da estrutura em árvore e serão condicionadas à realização das variáveis aleatórias até o instante da decisão e das decisões anteriormente tomadas. Desse modo, o problema de ALM apresentado nesta dissertação será resolvido com a utilização de metodologia de programação

\section{linear estocástica multiestágio mista inteira.}

Esta dissertação está estruturada conforme descrito a seguir. Neste primeiro capítulo, introduzimos o problema a ser desenvolvido abordando sua relação com a legislação aplicável aos fundos de pensão, os valores que estes devem respeitar, bem como a relação estreita entre ativo e passivo. Ainda na 
introdução, mencionamos a necessidade de contar eventos, a ser resolvida com a inserção de variáveis binárias, o que constitui a principal contribuição deste trabalho ao problema de ALM para a gestão de um plano de benefício de caráter previdenciário na modalidade de benefício definido. No capítulo 2, apresentamos uma breve revisão da literatura sobre o tema ALM. Nessa revisão, optamos por classificar o assunto não pela ordem cronológica, mas por temas e, dentro de cada tema, aí sim, pela ordem cronológica. Essa escolha tem como objetivo facilitar que o leitor encontre os objetos de seu interesse a partir dessa classificação específica. No capítulo 3, apresentamos o modelo matemático, sendo que este foi dividido em assuntos de modo a aproximá-lo da realidade objetiva da administração de um fundo de pensão. Nesse capítulo, a necessidade de inclusão de variáveis binárias para a solução de um problema específico ganha destaque. Cada restrição incluída é comentada, o que permite aproveitar a descrição feita no contexto específico de um fundo de pensão para outros problemas em que a necessidade de contar eventos esteja presente. O capítulo 4, uma vez que o problema de otimização estocástica se desenvolve no campo discreto, é reservado à descrição de árvore de cenários, forma utilizada para introdução das aleatoriedades encontradas no problema. Nesse capítulo, é também introduzida uma restrição fundamental, que impede a possibilidade de antecipar eventos futuros, denominada condição de não-antecipação. Além da descrição formal dessa condição, é apresentada também a sua forma algorítmica. O capítulo 5 é reservado à apresentação de dois exemplos especialmente preparados para esta dissertação. Cada um dos exemplos procura evidenciar o tratamento a ser dispensado quando um desequilíbrio excessivo e persistente é verificado. Nos dois exemplos, salientamos a necessidade da inclusão de variáveis binárias para a modelagem da contribuição extraordinária e da devolução de contribuição incluída no modelo matemático discutido no capítulo 4. Além de ativar a utilização de variáveis binárias, os exemplos têm também uma função educativa por apresentar ao gestor de um fundo de pensão a necessidade de elaborar um planejamento de longo prazo e as vantagens advindas dessa prática, que permite avaliar com antecedência a possibilidade de ocorrência de eventos extremos que, por certo, exigirão ações tempestivas de modo a não comprometer o patrimônio dos participantes. Finalmente, no capítulo 6, expomos as conclusões deste 
trabalho. Além disso, são propostas diversas sugestões de trabalhos futuros cuja preocupação seja a gestão conjunta dos ativos e passivos de um fundo de pensão.

Por fim, cumpre indicar que o código do problema apresentado nesta dissertação foi desenvolvido em linguagem AMPL [1] e que o software livre GLPK (GNU Linear Programming Kit) foi usado como solver. O pré e o pósprocessamento necessários, tais como a geração de cenários em árvore, a geração de dinâmicas estocásticas e a apresentação de resultados originados pelo software de otimização, foram todos trabalhados em linguagem MATLAB. 


\section{Revisão bibliográfica}

A administração de um plano de benefício de caráter previdenciário na modalidade de benefício definido - fundo de benefício definido - exige que o seu gestor delibere sobre o valor das contribuições e sobre a alocação dos recursos, de modo que os benefícios concedidos sejam pagos (visão de fluxo de caixa) e o equilíbrio e a solvência do plano sejam assegurados. Essas decisões devem considerar ainda as restrições impostas pelo Conselho Deliberativo da entidade e seu nível de tolerância ao risco. Consideradas a complexidade e relevância do problema, inúmeras são as referências técnicas que buscam auxiliar o gestor do fundo de pensão no processo de tomada de decisão. Nesta seção, vamos indicar algumas dessas manifestações, procurando evidenciar sua aderência à definição proposta pela SOA [2]. As referências serão organizadas por assunto e não em ordem cronológica. Essa escolha permite que o leitor oriente sua atenção para os assuntos que efetivamente lhe interessam.

\section{Casamento de fluxo de caixa; casamento de duração; modelos média-variância}

Uma forma simples de assegurar a tempestividade do pagamento dos benefícios já em curso - casamento de fluxo de caixa - consiste na aquisição de ativos cujo resgate ou pagamento de direitos ocorram na mesma data do pagamento dos benefícios aos assistidos e em volume suficiente para honrá-los. Dada a dificuldade de aquisição de ativos cujas maturidades coincidam com as datas de pagamento dos benefícios, essa estratégia é limitada. Em geral, ela é utilizada apenas para a cobertura dos benefícios cujos pagamentos ocorram em

prazos mais curtos. É fácil verificar que o equilíbrio alcançado com o casamento de fluxo de caixa é bastante sensível às variações da taxa de juros. 
Uma forma de contornar essa deficiência é utilizar a metodologia denominada casamento de duração ${ }^{1}$. É atribuído à F.M. Redington, atuário britânico nascido em 1906, a primeira referência ao termo imunização em finanças. Redington mostrou que, se a duração dos ativos e passivos são iguais e se outras condições envolvendo a distribuição dos fluxos de ativos e passivos em torno da duração forem verificadas, o portfólio está protegido contra uma variação local paralela na curva de juros. A técnica de imunização de portfólio está intimamente relacionada ao conceito de duração. Macaulay [3] definiu formalmente o conceito de duração e estabeleceu as condições gerais para a imunização de um portfólio. Uma boa descrição desse problema pode ser encontrada em James e Webber [4] e Fabozzi [5].

Os dois métodos anteriormente apresentados - casamento de fluxo de caixa e casamento de duração - foram tratados por Feldblum [6]. Nesse artigo, o autor discute ambos os problemas, apresentando suas vantagens e limitações. Sugere o autor que passivos com maior maturidade podem ser casados com ativos de renda variável por apresentarem maior duração. Infelizmente, as duas abordagens não consideram as condições de solvência e podem induzir o gestor a tomar decisões incompatíveis com a aversão ao risco típica dos fundos de pensão.

Os modelos média-variância, cujo mais famoso representante foi Harry Markowitz, são construídos buscando a maximização do retorno esperado de um portfólio dado um nível de risco ou a minimização do risco dado um valor para o retorno esperado do portfólio. Originalmente, esse problema foi resolvido considerando o horizonte temporal de apenas um período. A utilização do problema de Markowitz para a gestão do portfólio de um fundo de pensão apresenta, pelo menos, dois inconvenientes: (i) determina um portfólio ótimo considerando apenas um período de tempo, ao passo que o horizonte temporal de um fundo de pensão se estende por muitos períodos, e (ii) não considera as condições de liquidez e solvência. A primeira inconveniência foi contornada com

\footnotetext{
${ }^{1}$ Nesse caso, duração é a média das maturidades ponderadas pelo valor do fluxo de caixa. Formalmente, ela é descrita da seguinte maneira:

Se $B$ é um instrumento de renda fixa cujo valor depende de taxa de juros $\mathrm{r}$, sua duração $D$ é definida como

$$
D_{r}(B)=-\left.\frac{1}{B} \frac{\partial B}{\partial r}\right|_{r=r_{0}},
$$

onde $r_{0}$ representa a taxa de juros corrente.
} 
a elaboração de modelos multiperíodos. Uma referência a esse tema pode ser encontrada em Duan e Wan-Lung [7]. Nesse artigo, além de apresentarem a solução analítica para o problema média-variância multiperíodo, os autores descrevem um algoritmo para a determinação dos portfólios ótimos. A liquidez ${ }^{2} \mathrm{e}$ o equilíbrio ${ }^{3}$ são convenientemente tratados na abordagem multiperíodo. As condições de solvência também podem ser bem conduzidas pela seguinte exigência: a riqueza final esperada deve ser maior ou igual a uma medida do passivo de longo prazo dos participantes. O modelo média-variância multiperíodo apresenta todos os bons fundamentos indicados na Lei Complementar 109, contudo não considera a perspectiva do ativo e do passivo simultaneamente. Assim sendo, não podemos considerá-lo um genuíno modelo de ALM, conforme definido pela SOA [2].

Prajogi, Muralidhar e van der Wouden [8] avaliaram estratégias de hedge para investidores que tomam decisões sob a perspectiva de Markowitz, na qual apenas os ativos são relevantes para as decisões de investimentos. Mostraram os autores que portfólios ótimos construídos apenas sob a ótica dos ativos podem conduzir a decisões sub-ótimas caso a perspectiva do ativo-passivo tiver sido tratada simultaneamente. Embora o tratamento ativo-passivo seja significativamente mais complexo do que a consideração risco-retorno, os autores enfatizam as implicações da escolha do modelo inadequado.

\section{Modelos de programação estocástica}

O problema apresentado nesta dissertação poderia ter sido formulado como um problema determinístico. Essa escolha, que sem dúvida conduziria a uma enorme redução do esforço computacional empregado, apresenta como inconveniente a desconsideração da natureza aleatória presente nas variáveis relevantes ao problema em apreço. Para emprestar mais realismo à formulação adotada, uma vez que as variáveis financeiras e atuariais são aleatórias, optamos por tratá-lo como um problema de programação estocástica. Além disso, essa

\footnotetext{
${ }^{2}$ Para tanto, basta incluir, como uma das restrições do problema, um ativo, denominado caixa, que deve acumular em cada período valor suficiente para o pagamento dos benefícios devidos naquele período.

${ }^{3}$ Basta, nesse caso, exigir que, em cada período, o valor do portfólio seja pelo menos igual ao valor do passivo do plano.
} 
abordagem possibilita a determinação de soluções ótimas em problemas envolvendo incertezas. O esforço computacional é plenamente recompensado pela possibilidade de incluir relações probabilísticas, tanto na função objetivo quanto como restrições no problema de otimização. As variáveis aleatórias são introduzidas quer pela indicação de suas funções de distribuição ou por árvores de cenários, sendo esta última a postura adotada neste trabalho. A abordagem estocástica permite também estimar a distribuição das variáveis de decisão. Essa possibilidade é, sem dívida, um grande apelo em seu favor.

A crescente evolução tanto de software quanto de hardware permitiu a solução de problemas de otimização por meio de técnicas de programação estocástica, o que difundiu e popularizou a utilização dessa ferramenta de apoio à decisão.

Em 1998, Carino e Ziemba [9] utilizaram a metodologia de programação linear estocástica multiestágio para determinar uma política ótima de aplicação de recursos para uma seguradora japonesa ${ }^{4}$. A solução do problema foi obtida por um processo de otimização no qual os ativos e passivos da seguradora foram tratados conjuntamente.

O objetivo da seguradora era maximizar seu lucro de longo prazo. Foi, portanto, introduzida na função objetivo do problema de otimização a maximização do lucro de longo prazo esperado, subtraídas as eventuais penalizações impostas por violações de restrições incluídas no modelo. A distribuição de probabilidade dos parâmetros estocásticos considerados no modelo foi inserida pela utilização de cenários.

Esse tipo de abordagem é diferente daquela descrita nos modelos de programação linear. Chama a atenção que, no modelo apresentado para a solução do problema da seguradora, foram introduzidas, na função objetivo, variáveis estocásticas e uma função linear das variáveis de decisão. É a presença de variáveis estocásticas que transforma o problema de otimização em um problema de otimização estocástica. Outro elemento importante introduzido no trabalho de Carino e Ziemba [9] é a presença de variáveis que oneram a função objetivo do problema caso as restrições indicadas por elas sejam violadas. Essa abordagem

\footnotetext{
${ }^{4}$ Os conceitos de programação linear estocástica em dois e mais estágios (multiestágios) serão desenvolvidos posteriormente.
} 
caracteriza uma forma inteligente de introduzir restrições que, mesmo não sendo satisfeitas, não impedem que o problema tenha solução.

Carino, Myers e Ziemba [10] abordam o mesmo problema descrito em [9] aprofundando, porém, a descrição da metodologia de geração de cenários para os parâmetros estocásticos. Uma vez que o problema apresentado indicava uma política ótima de aplicação de recursos maximizadora do lucro esperado da seguradora e que essa política também poderia ser obtida pela abordagem médiavariância de Markowitz, os autores puderam comparar as soluções geradas pelas duas metodologias. Eles terminam por concluir a superioridade do método de programação linear estocástica multiestágio em relação à abordagem médiavariância de Markowitz. Essa é uma importante conclusão, uma vez que, sendo a primeira solução muito mais cara do que a segunda, há que se desenvolver argumentos convincentes em favor da adoção de modelos de programação linear estocástica multiestágio. As conclusões dos autores encerram a discussão.

A aleatoriedade envolvida no problema de programação linear estocástica, quando lidamos com variáveis aleatórias discretas, é representada por uma estrutura chamada árvore de cenários. Cada subdivisão dessa estrutura é denominada nó e coincide com os momentos em que decisões são tomadas. Tais decisões levam em consideração a incerteza representada pelas múltiplas trajetórias que têm origem naquele nó e são sempre condicionadas à realização das variáveis aleatórias e às decisões tomadas até o momento indicado pelo nó atual. Conforme exposto anteriormente, a possibilidade de introduzir aleatoriedade no problema de programação linear estocástica através de cenários com estrutura em árvore representa um papel fundamental nesse tipo de problema. Em [11], Kouwenberg desenvolveu diversas formas de geração de cenários. Nesse trabalho, o autor propôs também a geração de cenários para o passivo atuarial. $\mathrm{Na}$ abordagem indicada, o valor do benefício devido ao assistido é trazido a valor presente considerando, além da taxa de desconto, a probabilidade de ele estar vivo no momento em que tiver direito a recebê-lo. $\mathrm{O}$ autor conclui que o desempenho do modelo de programação estocástica multiestágio pode ser consideravelmente melhorado pela escolha do método adequado de geração de cenário.

Em [26], Mulvey também aborda o problema de otimização para investidores de longo prazo. Sobre o tema, o autor tece os comentários a seguir. 
- No ambiente multiestágio, o investidor pode ter informações antecipadas da ocorrência de eventos indesejados. Esse conhecimento permitirá que sejam implementadas ações para minimizar a probabilidade de ocorrência de tais eventos.

- Ativos que apresentem grande volatilidade no curto prazo provavelmente serão excluídos em uma perspectiva de um único estágio. Contudo, na abordagem multiestágio, sua inclusão pode representar uma redução do risco global do portfólio, considerando as volatilidades em prazos maiores permitidas por tal abordagem.

- Na estratégia clássica de rebalanceamento de portfólio, parte dos ganhos obtidos são consumidos no pagamento dos custos de transação envolvidos. Apenas com a solução de modelos de otimização multiestágio, as regras ótimas de rebalanceamento do portfólio podem ser determinadas.

Esses argumentos evidenciam a superioridade da abordagem multi-estágio em relação a abordagem de um único período. Embora o ambiente de processamento torne-se inegavelmente maior e mais complexo com a abordagem multiestágio, o gestor dos investimentos passa a ter um conhecimento a priori da evolução do portfólio e, principalmente, das transações indicadas no processo de otimização. Esse conhecimento prévio permite ao gestor focar sua atenção em como fazer uma vez que o que fazer já foi indicado pelo modelo de otimização.

\section{Restrições probabilísticas}

Nessa classe de problemas são introduzidas, como restrições, relações que envolvam a probabilidade de ocorrência de alguma função de uma variável de decisão. Essas restrições são, principalmente, de dois tipos:

- Chance Constrains - CC: Nesse tipo de restrição, a variável de decisão aparece no problema introduzida por alguma declaração que avalia probabilidades de eventos da seguinte forma: $-P_{\xi}[T(\xi) x-h(\xi) \geq 0] \geq \alpha$. Essa declaração implica a determinação da variável de decisão $x$ de tal forma que o evento $[T(\xi) x-h(\xi) \geq 0]$ tenha probabilidade limitada inferiormente 
por $\alpha$. Em geral, problemas com restrições desse tipo não pertencem à classe dos problemas de otimização convexa.

- Integrated Chance Constrains - ICC: Nesse tipo de restrição, a variável de decisão aparece no problema introduzida por alguma declaração que caracteriza o valor esperado de uma variável aleatória $-E_{\xi}[\zeta(x, \xi)]$.

Outras restrições semelhantes podem ser obtidas, contudo elas não serão utilizadas neste trabalho. Uma discussão pormenorizada dos modelos baseados em valores esperados, quantis, valor em risco e valor em risco condicional que envolvem funções de probabilidade é encontrada em Kall e Mayer [12]. Nesse livro, além da apresentação dos modelos, suas propriedades básicas também são discutidas. Nele, ainda figuram diversos algoritmos para a solução de problemas de programação estocástica.

Em sua tese para obtenção do grau de $\mathrm{PhD}$, Dert [13] utiliza as restrições probabilísticas do tipo Chance Constrains (CC) para descrever variáveis estocásticas a cuja ocorrência se quer atribuir uma baixa probabilidade. Embora de utilidade inquestionável, seu tratamento matemático no ambiente de otimização deixa a desejar. As condições adequadas de convexidade e continuidade nem sempre são satisfeitas. Birge e Louveaux, em um livro seminal sobre Programação Estocástica [14], abordam detalhadamente as variáveis probabilísticas.

Haneveld e Maarten van der Vlerk; e Haneveld, Streutker e Maarten van der Vlerk voltam a abordar o tema das restrições probabilísticas em [15] e [16], respectivamente. Esses trabalhos introduzem o conceito de Integrated Chance Constrains (ICC). Nesse tipo de restrição, em vez de exigir probabilidade baixa dos eventos indesejáveis, as restrições são estabelecidas impondo-se que o valor esperado daqueles eventos seja pequeno. Os autores desenvolvem também um algoritmo eficiente para a solução da classe de problemas em que estão presentes as condições $I C C$.

Drijver, Haneveld e Maarten van der Vlerk [17] também abordam o problema de ALM com a utilização de modelos com restrições probabilísticas. Os autores fazem uma detalhada descrição das variáveis do modelo de otimização. Nessa descrição, eles consideram que: (i) os ajustamentos são feitos pela taxa de contribuição a ser paga ao fundo de pensão e (ii) as realocações dos investimentos 
são feitas em vários pontos do horizonte de análise. Nesse artigo, são utilizadas restrições do tipo Chance Constrains. Contudo, os autores discutem ainda outro tipo de restrição, as denominadas Conditional Constrains. A introdução dessa restrição permite que, em casos extremos, decida-se pela utilização de instrumentos de derivativos financeiros ${ }^{5}$. O risco de tal decisão deve, no entanto, ser bem avaliado, consideradas as implicações da utilização de tais instrumentos.

A introdução de restrições probabilísticas nos modelos de programação estocástica representa um grande avanço nessa importante classe de problemas de otimização. Por meio dessa abordagem, riscos podem ser adequadamente avaliados através de declarações probabilísticas envolvendo os quantis da distribuição, valor em risco e valor em risco condicional. No entanto, três dificuldades impedem a utilização plena desses modelos: (i) nem sempre as condições de convexidade são atendidas; (ii) em alguns casos, algoritmos eficientes ainda não foram construídos; e (iii) a dimensão do problema pode implicar um impedimento para a solução desse tipo de problema.

\section{Programação dinâmica a tempo contínuo}

Até aqui, foram apresentados modelos matemáticos nos quais as decisões são tomadas em pontos discretos no tempo. Diferentemente desses modelos, na abordagem a tempo contínuo, as decisões são tomadas em qualquer ponto do conjunto $[0, T]$, onde $T$ representa o horizonte de planejamento. Nos problemas de programação dinâmica a tempo contínuo, as variáveis relevantes são apresentadas por meio de equações diferenciais estocásticas. Infelizmente, nem sempre tais equações podem ser resolvidas analiticamente. Nesses casos, há que se desenvolver procedimentos de simulação que permitam ao usuário dessa metodologia conhecer características da solução do problema. Glasserman aborda em [19] algumas dessas técnicas de simulação estocástica. Já Siegmann e Lucas [20] resolvem o problema de gerenciamento ótimo ativo-passivo usando programação dinâmica contínua. Nesse trabalho, seu objetivo é a minimização da contribuição dos participantes. Os autores explicitam as equações diferenciais que descrevem as dinâmicas do ativo e do processo de riqueza associado. Estabelecidas as

\footnotetext{
${ }^{5}$ O leitor interessado pode encontrar em Jonh Hull [18] informações básicas sobre derivativos financeiros.
} 
dinâmicas de evolução do valor dos ativos, é possível caracterizar o processo contínuo de contribuição. As equações de Hamilton-Jacobi-Belmman (HJB) associadas a esse processo podem então ser obtidas. As equações HJB estão bem descritas em Øksendal [21]. Korn e Korn [22] é outra referência obrigatória sobre cálculo estocástico. Nesse livro, de caráter introdutório, diversas aplicações em finanças são indicadas, inclusive a versão dinâmica do problema de portfólio de Harry Markowitz. Embora de extrema elegância, a abordagem a tempo contínuo nem sempre permite a obtenção de soluções fechadas. No entanto, pela precisão que pode resultar desta abordagem, é recomendável que os interessados no problema de ALM se dediquem ao desenvolvimento de tais modelos.

Em síntese, o problema de alocação ótima de ativos considerando os passivos existentes no ambiente de otimização estocástica multiestágio vem evoluindo com a introdução de recursos computacionais tanto de software quanto de hardware. As restrições úteis de natureza estocásticas também foram objeto de pesquisas, tendo evoluído para o estabelecimento de condições que reúnem os atributos desejáveis que possibilitam a solução no ambiente de otimização. Ainda há, porém, muito o que desenvolver na constituição de algoritmos eficientes para a solução de problemas reais de ALM. Conforme veremos neste trabalho, os problemas de verdadeiro interesse conduzirão a um número significativo de restrições e variáveis que exigirão software e hardware suficientemente robustos, capazes de suportar as elevadas dimensões que tais problemas podem assumir.

Do anteriormente exposto, apenas os modelos de programação estocástica com restrições probabilísticas atendem integralmente a todas as condições indicadas na definição de ALM. No entanto, é necessário introduzir variáveis inteiras a fim de determinar a contribuição extraordinária para cobrir os déficits ou devolver a contribuição em caso de sucessivos e elevados superávits. As dificuldades computacionais advindas dessa escolha são plenamente compensadas pela possibilidade dada ao gestor de tomar decisões tempestivas baseadas em um modelo matemático muito próximo àquele indicado para a gestão de um fundo de pensão permitido a operar no Brasil. 


\section{3}

\section{A descrição do problema}

\section{1}

\section{Alguns conceitos importantes}

O problema a ser resolvido, orientado para um plano de benefício de caráter previdenciário na modalidade de benefício definido (plano de benefício definido), tem dois objetivos: (i) determinar a menor contribuição a ser paga por participantes e patrocinadores e (ii) aplicar os recursos garantidores considerando o seu passivo atuarial e um conjunto de restrições impostas.

Conforme vimos, esse é um problema de ALM ao qual serão introduzidos critérios de otimalidade a fim de incluí-lo na classe dos problemas de programação linear estocástica multiestágio mista inteira. Ao longo deste capítulo, vamos indicar como surgem tais problemas e como sua solução pode ser construída.

O modelo matemático para a solução do problema indicará as decisões que serão tomadas sequencialmente durante o horizonte de planejamento aqui representado por $T$.

As indicações de natureza estocástica serão introduzidas no modelo por meio de cenários probabilísticos e representadas por uma estrutura denominada árvore de cenários. Uma árvore de cenários é uma estrutura constituída por nós ligados por um arco orientado, indicando assim o sentido da transição entre dois nós. O nó inicial, denominado nó raiz, representa a condição inicial conhecida. Já os nós folhas correspondem à etapa final. Uma sequência de nós partindo do nó inicial e terminando em uma folha é denominada cenário. Portanto, o número de cenários é igual ao número de folhas da árvore. Aos arcos que saem do mesmo nó são atribuídas probabilidades, e a soma dessas probabilidades é igual à unidade. As probabilidades de transição podem ser atribuídas, por exemplo, pela utilização de um modelo multinomial ou por qualquer outro modelo discreto. Outra forma de atribuir probabilidades a esses eventos é pela utilização de informações fornecidas por especialistas. Nesse caso, os diversos especialistas se reúnem e 
decidem, para cada nó da estrutura, qual o valor da probabilidade de transição. Esse último método tem aplicação limitada, principalmente se a árvore de cenários apresenta uma grande quantidade de nós. Por exemplo, para uma árvore binária com $T$ períodos enumerados por $\{0, \ldots, T\}$, deverão ser atribuídas $2^{(T+1)}-1$ probabilidades. Se $T$ for feito igual a 14 , representando um horizonte de planejamento de 15 anos, será necessário atribuir um total de 32.767 probabilidades. Considerada a magnitude desse valor, é recomendável atribuir probabilidades de transição por meio de uma distribuição de probabilidade com descrição analítica conhecida. É importante assinalar que cada nó da estrutura é caracterizado por um vetor de variáveis aleatórias cujo número de componentes é dado pelo número de variáveis aleatórias definidas no modelo. Desse modo, a transição entre dois nós representa a transição de um vetor aleatório multivariado.

A figura a seguir retrata uma visão esquemática do problema apresentado neste trabalho.

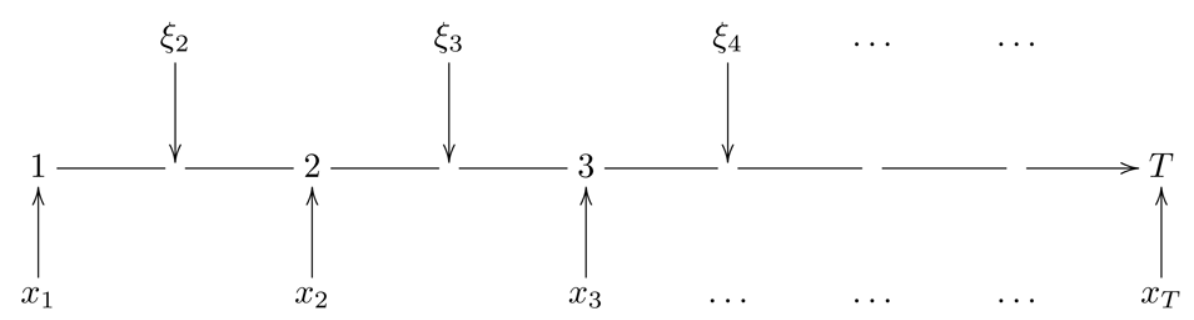

Figura 1: Dinâmica do processo de decisão

Nessa figura, $\left\{x_{1}, \ldots, x_{T}\right\}$ representam as decisões tomada nos instantes $\{1, \ldots, T\}$. No problema em questão, as variáveis de decisão representam o total das contribuições e o valor das compras e vendas de ativos.

As decisões que correspondem ao instante 1, caracterizadas pelo vetor $x_{1}$, serão tomadas antes que seja possível observar a realização das variáveis aleatórias. $\mathrm{O}$ vetor $x_{1}$ é, portanto, um vetor de variáveis determinísticas.

No instante $t=2$, uma nova decisão $x_{2}\left(x_{1} ; \xi_{2}\right)$ será tomada considerando as decisões $x_{1}$ e a realização do vetor aleatório $\xi_{2}$. É importante perceber que a ligação entre o tempo $t=1$ e o tempo $t=2$ é feita pelos arcos que saem do nó inicial. Portanto, as decisões $x_{2}\left(x_{1} ; \xi_{2}\right)$ serão tantas quantos forem os arcos que partem do nó inicial. Cada um desses arcos representa uma realização do vetor aleatório $\xi_{2}$. Esse é o modo pelo qual podemos formar o vetor $x_{2}\left(x_{1} ; \xi_{2}\right)$ após a 
observação da realização do vetor aleatório $\xi_{2}$. Observe ainda que a decisão $x_{2}\left(x_{1} ; \xi_{2}\right)$ será tomada no ambiente de incertezas caracterizadas pelos vetores aleatórios $\left\{\xi_{3}, \ldots, \xi_{T}\right\}$.

O processo se estende até o instante $T$, quando toda informação aleatória já tiver sido revelada. A decisão $x_{T}\left(x_{1}, \ldots, x_{T} ; \xi_{2}, \ldots, \xi_{T}\right)$ envolve, então, além da revelação de toda a dinâmica estocástica, todas as decisões anteriormente tomadas.

Na Figura $1,\left\{x_{j}\left(x_{1}, \ldots, x_{j} ; \xi_{2}, \ldots, \xi_{j}\right) ; j=1, \ldots, T\right\}$ representa o j-ésimo vetor de decisão do problema de otimização. Esse vetor explicita a contribuição ótima a ser praticada entre os anos $j e j+1$, sendo $0 \leq j \leq T-1$, e o valor das compras e vendas de cada ativo efetuadas no tempo $j$.

O modelo de programação linear estocástica multiestágio está representado conforme indicado a seguir:

$$
\begin{aligned}
\min z & =c_{1}^{T} x_{1}+E\left[\sum_{t=2}^{T} c_{t}^{T} x_{t}\left(\xi_{t}\right)\right], \\
\text { sujeito } a: A_{11} x_{1} & =b_{1} \\
A_{t 1}\left(\xi_{1}\right) x_{1}+\left[\sum_{\tau=2}^{t} A_{t \tau}\left(\xi_{t}\right) x_{\tau}\left(\xi_{\tau}\right)\right] & =b_{t}\left(\xi_{t}\right), t=2, \ldots, T, \\
x_{1} ; x_{t}\left(\xi_{t}\right) & \geq 0,
\end{aligned}
$$

onde $c_{1}, x_{1}, A_{11}$ e $b_{1}$ são matrizes determinísticas de dimensões adequadas; as matrizes $A_{t \tau}\left(\xi_{t}\right), x_{\tau}\left(\xi_{\tau}\right)$ e $b_{t}\left(\xi_{t}\right)$ são matrizes aleatórias; e $E$ representa o operador valor esperado. O problema aqui apresentado é um problema de otimização estocástica multiestágio.

No primeiro estágio, é atribuído um valor ao vetor determinístico $x_{1}$. Nos estágios subsequentes, os vetores $x_{t}\left(x_{1}, \ldots, x_{t-1} ; \xi_{2}, \ldots, \xi_{t}\right)$ serão sequencialmente determinados à medida que as informações aleatórias $\xi_{t}$ forem sendo reveladas e depois de consideradas as decisões anteriores.

Neste ponto é conveniente chamar a atenção para as variáveis aleatórias envolvidas no problema de otimização estocástica. Caso tais variáveis sejam contínuas ou discretas não-enumeráveis, conforme indicado em James [23] a solução do problema é de grande complexidade. Contudo, se as variáveis 
aleatórias são do tipo discreto, o problema de otimização estocástica pode, sob certas condições, ser transformado em um problema equivalente, porém determinístico.

No problema que vamos resolver, os eventos aleatórios são discretos enumeráveis e serão introduzidos pela estruturação de uma árvore de cenários. Conforme já comentamos, as decisões serão tomadas sequencialmente. Isso significa que, em cada momento, a decisão a ser tomada deverá ser formada considerando tudo o que aconteceu até aquele instante. Contudo, não nos é possível antecipar o futuro. Essa última condição é denominada condição de nãoantecipação

Considerando um espaço de probabilidade $(\Omega, \mathcal{F}, P)$, onde $\Omega$ indica o espaço amostral do experimento, $\mathcal{F}$ a classe de eventos a qual queremos atribuir probabilidades e $P$ uma medida de probabilidade sobre $\mathcal{F}$, o modelo em construção exigirá que o espaço de probabilidade seja definido em cada instante de tempo. A construção do arcabouço formal onde esse problema se desenvolve abrange conceitos de processos estocásticos, notadamente os conceitos de $\sigma$ álgebra de eventos, filtração e funções mensuráveis definidas em uma $\sigma$-álgebra de eventos. Essas considerações, que fogem ao escopo deste trabalho, podem ser encontradas em Øksendal [21] e Pliska [24]. Vamos agora considerar um exemplo dos conceitos até aqui apresentados.

\section{Exemplo 1: Problema de alocação de recursos}

Considere que um investidor pode aplicar recursos financeiros em $n$ ativos indicados por $1, \ldots, n$. No início de cada período, representados por $t=1$, $t=2$ e $t=3$, as decisões de investimentos são tomadas respeitados os limites mínimos e máximos de investimentos nos ativos considerados. Não são permitidas compras a descoberto nem vendas a futuro. As decisões devem ser tomadas de modo a maximizar o valor presente da riqueza do investidor em $t=3$. A composição do portfólio em $t=0$ é conhecida. 


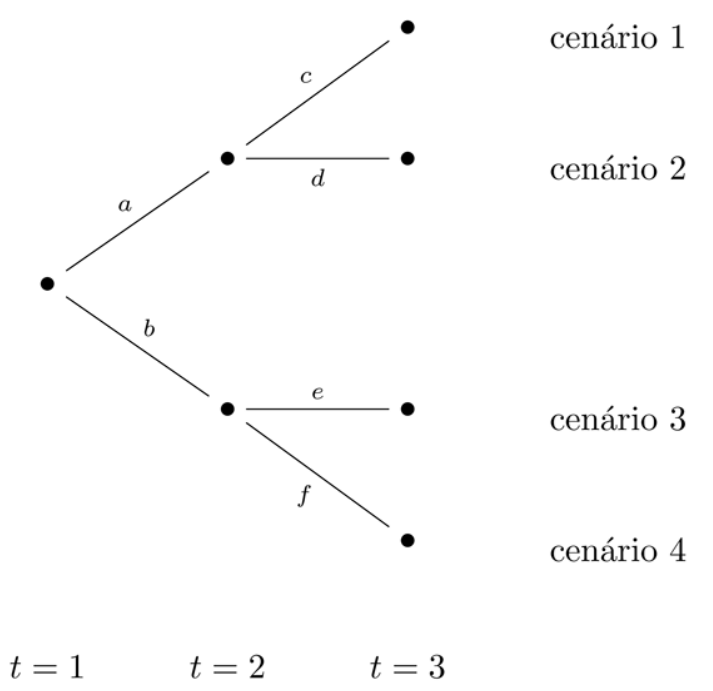

Figura 2: Estrutura em árvore - enumeração dos cenários

Neste exemplo, bastante simples, cada cenário é caracterizado por uma sequência de letras. Por exemplo, o cenário 4 é dado pela sequencia $(b, f)$.

\section{Variáveis de decisão:}

$c_{j, t}^{S}=$ valor das compras do ativo $j$ efetuadas no ano $t$ considerado o cenário $s ; \mathrm{e}$

$v_{j, t}^{S}=$ valor das vendas do ativo $j$ efetuadas no ano $t$ considerado o cenário $s$.

\section{Variáveis definidas pelo gestor:}

$l_{j, t}^{S}=$ limite inferior, em forma decimal, do ativo $j$ no ano $t$ considerado o cenário $s$;

$L_{j, t}^{S}=$ limite superior, em forma decimal, do ativo $j$ no ano $t$ considerado o cenário $s$; e

$r \quad=$ taxa de desconto financeiro.

\section{Variáveis aleatórias:}

$r_{j, t}^{S}=$ retorno, em forma decimal, do ativo $j$ avaliado no ano $t$ considerado o cenário $s$. 


\section{Outras variáveis relevantes:}

$X_{j, t}^{s}=$ valor investido no ativo $j$ no ano $t$ considerado o cenário $s$; e

$X_{j, 0}^{S}=$ valor inicial investido no ativo $j$ considerado o cenário $s$.

A equação que descreve a evolução dos ativos é indicada pela expressão a abaixo:

$$
X_{j, t}^{S}=X_{j, t-1}^{S}\left(1+r_{j, t-1}^{S}\right)+c_{j, t}^{S}-v_{j, t}^{S}
$$

A equação (3.5) indica que o valor do j-ésimo ativo no ano $t$ é dado pelo seu valor no ano anterior acrescido da remuneração devida pela sua posse e das compras realizadas no ano $t$ menos as vendas efetuadas naquele ano.

$$
\begin{aligned}
\sum_{j=1}^{n} c_{j, t}^{s} & \leq \sum_{j=1}^{n} X_{j, t-1}^{s}\left(1+r_{j, t-1}^{s}\right), \\
v_{j, t}^{S} & \leq X_{j, t-1}^{s}\left(1+r_{j, t-1}^{s}\right), \\
l_{j, t}^{s} \sum_{j=1}^{n} X_{j, t}^{s} & \leq X_{j, t}^{s}, \\
X_{j, t}^{s} & \leq L_{j, t}^{s} \sum_{j=1}^{n} X_{j, t}^{s}, \\
c_{j, t}^{S} & \geq 0, \\
v_{j, t}^{s} & \geq 0, \\
j & =1, \ldots, 4, \\
t & =1,2,3, \\
s & =1,2,3,4 .
\end{aligned}
$$

A inequação (3.6) estabelece que o total das compras efetuadas em qualquer instante $t$ não pode superar o valor de mercado do conjunto dos ativos do investidor no instante anterior acrescido do ganho de capital originado pela posse desses ativos. Ademais, a condição estabelece que não podemos comprar mais do que o valor de mercado do portfólio do investidor. 
Uma condição semelhante, indicada pela inequação (3.7), estabelece que o total das vendas do ativo $j$ no instante $t$ não pode exceder o seu valor. Essa inequação representa a condição que impede o investidor de fazer vendas a descoberto ou a futuro.

As inequações (3.8) e (3.9) caracterizam, respectivamente, os limites inferior e superior para aplicação no ativo $j$ que foram impostas pelo gestor e devem ser respeitados pelo investidor.

Indicaremos agora um conjunto de restrições que caracterizam um problema de otimização estocástica multiperíodo. Vamos imaginar que serão tomadas as decisões do período $t=2$ e que o arco $b$ tenha alcançado esse nó (Figura 2). Nessas circunstâncias, o investidor sabe apenas que os cenários 3 ou 4 podem ser alcançados, contudo, a ocorrência de um ou outro é aleatória e, sendo assim, só será revelada em $t=3$. Isso implica que a decisão tomada nesse nó é a mesma para o cenário 3 ou 4. Essa circunstância é denominada condição de nãoantecipação. Formalmente, ela é descrita da seguinte forma:

$$
x_{j, t}^{s 1}=x_{j, t}^{s 2}
$$

se as trajetórias que levam as duas variáveis ao nó $t$ forem idênticas.

Devemos então introduzir as condições de não-antecipação e completar o conjunto de restrições do problema de alocação de recursos.

$$
\begin{aligned}
c_{j, 1}^{1}=c_{j, 1}^{2}= & c_{j, 1}^{3}=c_{j, 1}^{4}, \\
v_{j, 1}^{1}=v_{j, 1}^{2}=v_{j, 1}^{3} & =v_{j, 1}^{4}, \\
& c_{j, 2}^{1}=c_{j, 2}^{2}, \\
c_{j, 2}^{3} & =c_{j, 2}^{4}, \\
v_{j, 2}^{1} & =v_{j, 2}^{2}, \\
v_{j, 2}^{3} & =v_{j, 2}^{4} .
\end{aligned}
$$

Determinadas todas as restrições do problema, inclusive as condições de nãoantecipação, estamos agora em condições de estabelecer a função objetivo do 
problema de alocação de recursos. Nosso objetivo é maximizar o valor esperado do valor presente da riqueza final do investidor. Algebricamente, queremos maximizar a seguinte função:

$$
\sum_{s=1}^{4} p_{s}\left[\sum_{j=1}^{n} X_{j, 3}^{s}\right](1+r)^{-3}
$$

onde $p_{s}$ representa as probabilidades dos cenários considerados e $r$ indica a taxa de desconto financeiro corrente em $t=3$. Observe que, na expressão (3.22), a soma do produto de $p_{s}$ pelo termo entre colchetes corresponde, no caso de uma variável aleatória discreta, à expectância da variável considerada. Como as variáveis de decisão são as compras e vendas, devemos reescrever (3.22) de modo a incluí-las explicitamente. Esse esforço conduz à expressão a seguir:

$$
\sum_{s=1}^{4} p_{s}\left\{\sum_{j=1}^{n}\left[\sum_{r=1}^{2}\left(c_{j, \tau}^{s}-v_{j, \tau}^{s}\right) \prod_{k=\tau}^{2}\left(1+r_{j, k}^{s}\right)+\left(c_{j, 3}^{s}-v_{j, 3}^{s}\right)\right]\right\}(1+r)^{-3}
$$

A expressão (3.23), que representa a função objetivo a ser maximizada no problema de alocação de recursos, é equivalente à expressão (3.22), na qual $X_{j, 3}^{S}$ foi explicitado em função das compras e vendas efetuadas até o ano $t=3$. A partir de (3.22), com algum esforço algébrico, é possível determinar a expressão (3.23).

\section{2}

\section{O modelo matemático}

Neste trabalho, apresentaremos ao gestor de um plano de benefício de caráter previdenciário na modalidade de benefício definido uma política ótima de compra e venda de ativos para cada ano do horizonte de planejamento.

Nossa política é ótima uma vez que o modelo correspondente minimiza a contribuição paga por participantes e patrocinadores. Nesse caso, a compra e venda de ativos, assim como o total das contribuições, serão incluídos como variáveis de decisão. 
Vamos considerar um horizonte de planejamento de $T$ anos que especifica o número de períodos em que decisões sucessivas, que levam em conta as despesas do fundo de pensão e seu passivo atuarial, serão tomadas.

A cada ano, contribuições serão pagas por participantes e patrocinadores, benefícios serão pagos aos participantes e, eventualmente, contribuições poderão ser devolvidas aos participantes ou contribuições extraordinárias poderão ser cobradas de participantes e patrocinadores. No final de cada ano, será apurado o valor do ativo e do passivo atuarial do fundo de pensão. Conhecidos esses elementos, é possível determinar o valor da relação $A_{t} / L_{t}$ e decidir o valor da contribuição a ser paga ou devolvida aos participantes. A seguir, indicamos a sequência de ações consideradas no problema:

- A cada ano, será indicada a composição ótima do portfólio do fundo de pensão.

- A taxa de contribuição normal a ser paga pelos participantes e patrocinadores será anualmente determinada. Na modelagem, serão introduzidos elementos que evitem que as contribuições sejam alteradas bruscamente.

- Caso seja verificado que a razão $A_{t} / L_{t}$ se manteve abaixo de certo valor indicado pelo gestor durante a períodos consecutivos, será cobrada uma contribuição extraordinária dos participantes e patrocinadores com vistas a cobrir a insuficiência observada.

- Caso seja verificado que a razão $A_{t} / L_{t}$ se manteve acima de certo valor indicado pelo gestor durante b períodos consecutivos, parte desse excesso será devolvido aos participantes e patrocinadores.

O modelo será desenvolvido considerando cenários com consistência macroeconômica que reflitam o ambiente futuro em que as decisões serão tomadas. Por hipótese, existe um total de $S$ cenários, $N$ ativos financeiros, e as decisões deverão ser tomadas anualmente durante $T$ anos consecutivos. Desse modo, os índices $t \in\{1,2, \ldots, T\} ; \quad s \in\{1,2, \ldots, S\} ; \quad$ e $j \in\{1,2, \ldots, N\}$ representam, respectivamente, o tempo, o cenário considerado e o ativo financeiro. 
Antes de avançar na apresentação do problema, é necessário que sejam feitas algumas considerações sobre o ano $t$, o instante $t$ e o que ocorre de relevante nessas duas referências de tempo.

1. Ano $t$ é o intervalo de tempo compreendido entre o instante $t$ e o instante $t+1$. Matematicamente, ele será representado pelo intervalo semiaberto: $[t, t+1)$.

2. No instante $\boldsymbol{t}$, para cada cenário considerado, são avaliados o ativo $A_{t}$ e o passivo $L_{t}$.

3. Conhecidos $A_{t}$ e $L_{t}$, é possível determinar a contribuição normal $c_{t}$, a contribuirão extraordinária $Z_{t}$ e a devolução de contribuição $V_{t}$.

4. As variáveis de decisão $c_{t}, Z_{t}$ e $V_{t}$ serão pagas no ano $t$.

5. No ano $\boldsymbol{t}$, são decididos os valores das compras $\boldsymbol{X} \boldsymbol{C}_{\boldsymbol{j}, \boldsymbol{t}}$ e das vendas $\boldsymbol{X} \boldsymbol{V}_{\boldsymbol{j}, \boldsymbol{t}}$ do ativo $j$.

6. Os ativos são avaliados no instante $\boldsymbol{t}$, ou seja, durante o ano $\boldsymbol{t}$, toda a remuneração devida em razão da posse do ativo $X_{j, t}$ será adicionada ao valor do ativo. Assim, no instante $\boldsymbol{t}+\mathbf{1}$, seu valor será: $\left(1+r_{j, t}\right) X_{j, t}$.

Na verdade, tanto o ativo $A_{t}$ como o passivo $L_{t}$, ambos referentes ao ano $\boldsymbol{t}$, são determinados apenas nos meses iniciais do ano $\boldsymbol{t}+\mathbf{1}$. Esse é o prazo necessário para que atuários, contadores, auditores e demais profissionais envolvidos ultimem suas avaliações e as disponibilizem para os colegiados competentes, participantes e patrocinadores.

Feitas essas considerações, vamos indicar as variáveis que serão utilizadas no problema.

\section{Variáveis Aleatórias:}

$r_{j, t}^{S}=$ retorno, em forma decimal, do ativo $j$ avaliado no ano $t$ considerado o cenário $s$;

$B_{t}^{s} \quad=\quad$ valor dos benefícios pagos no ano $t$ considerado o cenário $s$;

$L_{t}^{s} \quad=\quad$ valor do passivo dos participantes no ano $t$ considerado o cenário $s ; \mathrm{e}$

$W_{t}^{s}=$ total da folha de salário dos participantes avaliada no ano $t$ considerado o cenário $s$. 


\section{Variáveis de decisão:}

$$
\begin{aligned}
\boldsymbol{X} \boldsymbol{C}_{t, j}^{s}= & \text { valor comprado do ativo } j \text { no ano } t \text { considerado o cenário } s ; \\
\boldsymbol{X} \boldsymbol{V}_{t, j}^{s}= & \text { valor vendido do ativo } j \text { no ano } t \text { considerado o cenário } s ; \\
\boldsymbol{c}_{t}^{s}= & \text { taxa de contribuição para o ano } t \text { considerado o cenário } s ; \\
\boldsymbol{Z}_{t}^{s}= & \text { valor da contribuição extraordinária a ser paga no ano } t \\
& \quad \text { considerado o cenário } s ; \\
\boldsymbol{V}_{t}^{s}= & \text { valor da contribuição extraordinária a ser devolvida no ano } t \\
& \text { considerado o cenário } s ; \text { e } \\
\boldsymbol{z}_{t}^{s}, \boldsymbol{u}_{t}^{s}, \boldsymbol{o}_{t}^{s}, \boldsymbol{v}_{t}^{s}= & \text { variáveis inteiras que assumem valores } 0 \text { ou } 1 .
\end{aligned}
$$

\section{Outras variáveis relevantes:}

$$
\begin{aligned}
& A_{t}^{S}=\text { total do ativo do fundo de pensão avaliado no ano } t \text { considerado } \\
& \text { o cenário } s \text {; } \\
& A_{t}^{S} / L_{t}^{S}=\text { índice de solvência do fundo de pensão avaliado no ano } t \\
& \text { considerado o cenário } s \text {; e } \\
& X_{j, t}^{S}=\text { valor investido pelo fundo de pensão no ativo } j \text { no ano } t \\
& \text { considerado o cenário } s \text {. }
\end{aligned}
$$

\section{Constantes definidas pelo gestor:}

$\overline{\boldsymbol{f}_{\boldsymbol{j}}}=$ limite superior permitido para o ativo $j$, expresso como percentual do ativo total;

$\underline{\boldsymbol{f}_{\boldsymbol{j}}}=$ limite inferior permitido para o ativo $j$, expresso como percentual do ativo total;

$\boldsymbol{k}_{\boldsymbol{j}}=$ custo de transação, isto é, percentual incidente sobre o valor negociado do ativo $j$;

$j=$ taxa de juros considerada nos empréstimos a participantes;

$\mathrm{Y}_{t}^{s}=$ fator de desconto financeiro no ano $t$ considerado o cenário $s ; \mathrm{e}$,

$M=$ valor muito grande.

Uma vez que a variável de decisão correspondente à taxa de contribuição desempenha um papel fundamental nos planos de benefício de caráter 
previdenciário na modalidade de benefício definido, vamos fazer alguns comentários adicionais a seu respeito.

A taxa de contribuição normal paga pelos participantes corresponde a um percentual $c_{t}^{S}$ que incide sobre o total $W_{t}^{S}$ da folha de salário dos participantes ativos avaliada no ano $t$. Assim sendo, a receita de contribuição recebida pelo fundo de pensão é então $c_{t}^{S} W_{t}^{S}$. A determinação de $c_{t}^{S}$ exige a apuração da situação patrimonial do fundo, mais precisamente, da relação $A_{t} / L_{t}$. Uma vez apurada essa relação, o gestor pode determinar a taxa de contribuição a ser praticada no ano $t$. Além da contribuição paga pelos participantes, é comum que os assistidos e os patrocinadores também façam contribuições para o fundo de pensão. Neste trabalho, as contribuições dos participantes, patrocinadores e assistidos serão consideradas como um único objeto denominado contribuição. A forma de ratear essa contribuição entre as partes envolvidas não será considerada neste trabalho, visto que a matéria está descrita no plano de custeio do fundo de pensão.

No regulamento do fundo de pensão, está descrito o valor da contribuição dos participantes, geralmente indicado como um percentual da sua folha de salário, além de outros elementos que definem a contribuição dos patrocinadores e dos assistidos. Também é comum a indicação dos limites inferior e superior entre os quais a taxa de contribuição pode oscilar livremente. A seguinte desigualdade deve ser introduzida no modelo de otimização:

$$
\underline{c} \leq c_{t}^{S} \leq \bar{c}
$$

onde $\underline{c}$ representa o limite inferior e $\bar{c}$, o limite superior da contribuição normal.

A contribuição resultante, desde que restrita aos limites estabelecidos em (3.24), será denominada contribuição normal. Caso o limite superior estabelecido na relação (3.24) seja violado, há que se exigir tanto dos participantes quanto dos patrocinadores um esforço contributivo, conforme será explicitado mais adiante. De modo semelhante, caso o patrimônio dos participantes do fundo revele-se muito superior ao necessário, parte desse excesso será devolvido aos participantes. Essa hipótese também será tratada oportunamente. 


\subsection{1}

\section{Contribuição normal}

Participantes e patrocinadores pagam regularmente ao fundo de pensão um percentual incidente sobre a massa salarial total a título de contribuição normal. Essa taxa de contribuição é atuarialmente determinada e corresponde, coeteris paribus, à taxa justa para a manutenção do equilíbrio atuarial e da solvência do fundo de pensão.

$\mathrm{Na}$ determinação da taxa de contribuição $c_{t}^{s}$ para os exercícios seguintes, os dirigentes do fundo de pensão consideram não apenas a situação patrimonial do fundo naquele instante como também outras condições relevantes (taxa de desconto atuarial, política salarial da patrocinadora, política de recursos humanos da patrocinadora etc.), que exercem grande influência na liquidez, equilíbrio e solvência do fundo de pensão.

Uma vez determinada a taxa de contribuição a ser paga, é preciso evitar que ela sofra variações ao longo do tempo. Infelizmente, isso nem sempre pode ser garantido. Tendo em vista esses casos, introduziremos elementos no modelo que penalizem variações excessivas na taxa de contribuição.

Embora a taxa de contribuição possa ser fixada livremente pelos gestores do fundo de pensão, ela deve ser limitada inferior e superiormente. O limite inferior $\underline{c}$, adotado em nosso modelo, independe do tempo e do cenário e representa o valor mínimo que ainda permita ao fundo de pensão continuar suas operações. Esse limite inferior pode representar, por exemplo, o total do custo fixo do fundo de pensão. O limite superior $\bar{c}$ representa a maior contribuição que pode ser suportada pelos participantes e patrocinadores. O limite superior também é independente do cenário e do tempo. Esses dois limites são fixados atuarialmente, devem constar do plano de custeio do fundo de pensão e devem, ainda, ser de conhecimento dos participantes e patrocinadores.

Além de se preocupar em manter as contribuições entre os limites estabelecidos em (3.24), o gestor deve também tratar de mantê-las estáveis ao longo do tempo. Essa estabilidade será descrita pela diferença entre as taxas de contribuição pagas em dois anos consecutivos. A condição de estabilidade, que deve respeitar a desigualdade (3.24), será introduzida na função objetivo na forma 
de penalização. Essa condição será representada pelo par de desigualdades indicadas a seguir:

$$
-\eta \leq c_{t}^{S}-c_{t-1}^{s} \leq \rho
$$

onde $c_{t}^{S}-c_{t-1}^{S}$ representa a variação na taxa de contribuição entre dois anos consecutivos e $\eta$ e $\rho$ são grandezas positivas que representam os limites fixos para variação da taxa de contribuição entre dois períodos consecutivos.

As condições impostas pela desigualdade (3.25) não substituem aquelas descritas em (3.24). Na verdade, enquanto (3.24) impõe uma obrigação a ser respeitada (restrição dura), a desigualdade (3.25) representa apenas um desejo do gestor do fundo de pensão (restrição suave). Caso seja necessário violar os limites impostos em (3.25), o modelo matemático não impede que o gestor tome tal decisão desde que o equilíbrio do fundo de pensão seja preservado. Vamos então modelar essa penalização de modo que seja possível tratá-la no contexto da programação linear. Antes de descrever algoritmicamente essas condições especiais, vamos introduzir a útil representação válida para um real $x$ qualquer:

$$
\begin{aligned}
& (x)^{+}=\max \{0, x\}, \\
& (x)^{-}=\max \{0,-x\} .
\end{aligned}
$$

Agora podemos voltar às condições (3.25). Inicialmente vamos considerar o lado esquerdo da desigualdade. Nesse caso, queremos evitar que

$$
-\eta>c_{t}^{S}-c_{t-1}^{S}
$$

ou, equivalentemente, que

$$
-\eta<c_{t-1}^{s}-c_{t}^{S}
$$

A desigualdade (3.27) pode ser escrita na forma $\left(c_{t-1}^{s}-c_{t}^{s}-\eta\right)^{+}$. Neste momento, vamos introduzir uma variável de decisão, $c d_{t}^{s}$, positiva ou nula e as seguintes restrições: 


$$
\begin{aligned}
\eta+c d_{t}^{s} & \geq c_{t-1}^{s}-c_{t}^{s} \\
c d_{t}^{s} & \geq 0
\end{aligned}
$$

A variável $c d_{t}^{S}$ ou um múltiplo positivo seu deverão ser incluídos na função objetivo do problema de minimização. Vamos entender a lógica das desigualdades (3.28) e (3.29). Suponhamos que, no caso $1, \eta$ seja igual a 0,03 e $\left(c_{t-1}^{S}-c_{t}^{S}\right)$, igual a 0,07 . Nesse caso, a diferença entre duas contribuições consecutivas é menor do que o limite inferior $-\eta$. Assim, a desigualdade (3.28) conduzirá à determinação de que $c d_{t}^{S}$ seja maior do que 0 ou então, dependendo dos custos envolvidos, o valor de $c_{t}^{s}$ deverá ser aumentado. No caso 2, vamos supor que $\eta$ seja igual a 0,03 e que $\left(c_{t-1}^{s}-c_{t}^{s}\right)$, igual a 0,02 . Nesse caso, $c d_{t}^{s}$ será feito igual a 0 uma vez que a diferença de contribuições consecutivas excedeu o limite inferior $-\eta$. Os dois exemplos esclarecem por que uma nova variável de decisão $c d_{t}^{S}$ foi introduzida no modelo. Vale observar que nem sempre a solução ótima permite aumentar $c_{t}^{S}$ conforme sugerido no caso 1 . Nessas circunstâncias, o lado esquerdo de (3.25) será violado sem contudo impedir que o problema tenha solução. Isso é o que justifica denominar tais restrições de suaves.

Vamos agora considerar a desigualdade $c_{t}^{s}-c_{t-1}^{s} \leq \rho$. Essa situação é idêntica a $-\eta \leq c_{t}^{S}-c_{t-1}^{S}$, tratada anteriormente. No entanto, vamos tratá-la como nova e introduzir a solução considerando a função $(.)^{+}$. Essa situação se caracteriza pela intenção de evitar uma variação excessiva na taxa de contribuição em dois períodos consecutivos. Agora vamos considerar a seguinte desigualdade:

$$
c_{t}^{S}-c_{t-1}^{S}-\rho>0
$$

Caso a desigualdade (3.30) se verifique, é porque o lado direito de (3.25) foi desrespeitado. Nesse caso, a seguinte relação deverá ser penalizada: $\left(c_{t}^{S}-c_{t-1}^{S}-\rho\right)^{+}$. Como essa equação não pode ser resolvida no contexto da programação linear, é preciso criar outra variável de decisão, $c i_{t}^{S}$, a ser tomada em seu valor máximo, que deverá satisfazer a seguinte condição:

$$
\rho+c i_{t}^{S} \geq c_{t}^{S}-c_{t-1}^{S}
$$


Pelos mesmos motivos já expostos, devemos impor adicionalmente que $c i_{t}^{s}$ seja maior ou igual a 0 . Para isso, o par de desigualdades a seguir deverá ser introduzido no problema de otimização:

$$
\begin{aligned}
& c i_{t}^{S} \geq c_{t}^{S}-c_{t-1}^{S}-\rho, \\
& c i_{t}^{S} \geq 0 .
\end{aligned}
$$

Por fim, é importante reafirmar que a restrição (3.25) não substitui a condição (3.24). A primeira é uma restrição que deve ser satisfeita - restrição dura - enquanto a segunda será incluída onerando a função objetivo - restrição suave. $\mathrm{Na}$ verdade, queremos evitar oscilações extremas tanto para elevar como para reduzir a contribuição. O primeiro caso ocorrerá quando $c_{t}^{S}-c_{t-1}^{S}-\rho>0$, já o segundo, quando $c_{t}^{S}-c_{t-1}^{S}+\eta<0$. Na função objetivo devemos incluir:

$$
\left(\xi_{c i} c i_{t}^{s}+\xi_{c d} c d_{t}^{s}\right) W_{t}^{s}
$$

Os parâmetros $\xi_{c i}$ e $\xi_{c d}$ serão indicados pelo gestor, devendo ainda respeitar a relação $\xi_{c i} \geq \xi_{c d}$, uma vez que participantes e patrocinadores resistirão mais ao aumento de contribuição do que à sua redução.

A introdução da condição (3.34) na função objetivo representa uma forma elegante de evitar variações bruscas na taxa de contribuição devida. Além disso, permite que o gestor, ao administrar os parâmetros $\eta$ e $\rho$, pratique uma política ativa de gestão de contribuições capaz de reduzir o risco de uma possível necessidade de impor aos participantes e patrocinadores a realização de uma contribuição extraordinária.

\section{2 .2}

\section{Contribuição extraordinária}

Agora será modelada a situação em que o fundo de pensão, como consequência de variações de ativo e passivo desiguais, acumula um ativo total inferior ao passivo dos participantes. Apresentaremos uma abordagem mais abrangente do que a simples constatação da ocorrência de um déficit. Em vez disso, será desenvolvido um modelo matemático em que apenas a repetição de 
valores da relação $A_{t} / L_{t}$ abaixo de um valor previamente especificado pelo gestor implicará uma ação do gestor para a superação de tal situação indesejável. Nossa intenção é oferecer ao gestor do fundo de pensão a possibilidade de praticar uma administração ativa dos recursos garantidores e, desse modo, evitar o surgimento de um déficit que o obrigue a cumprir o disposto na Resolução CGPC n $^{0}$ 26, de 29 de setembro de 2008, que dispõe sobre o equacionamento do déficit dos planos de benefício.

Uma vez verificado um déficit, os gestores do fundo de pensão deverão tomar atitudes imediatas com vistas ao reestabelecimento do equilíbrio atuarial. A legislação apresenta três formas de equacionamento do desequilíbrio: (i) aumentar o valor das contribuições, (ii) instituir uma contribuição adicional ou (iii) reduzir o valor dos benefícios a conceder. A elevação da contribuição já está sendo considerada pelo conjunto das restrições incluídas no modelo. A redução do benefício não será tratada neste trabalho e deverá ser usada apenas caso as demais alternativas sejam insuficientes. Por fim, resta a alternativa de cobrança de uma contribuição adicional, questão que será abordada neste ponto. Queremos evitar que o evento

$$
\frac{A_{t}^{S}}{L_{t}^{s}}<\alpha
$$

ocorra muitas vezes com $\alpha \geq 1$. Tornando essa afirmação mais precisa, o que vamos fazer é reestabelecer a igualdade $A_{t}^{S} / L_{t}^{S} \leq \alpha$ sempre que (3.35) ocorrer a vezes consecutivas, onde a é um inteiro indicado pelo gestor. Essa abordagem apresenta ao menos dois atrativos: (i) previne a ocorrência de déficit e (ii) permite que as circunstâncias que conduziram ao evento (3.35) possam ser revertidas. $\mathrm{Na}$ hipótese de ocorrência de (3.35) durante a anos consecutivos, será cobrado de participantes e patrocinadores uma contribuição extraordinária de valor pelo menos igual a $\left(\alpha L_{t}^{S}-A_{t}^{S}\right)$. Uma vez pago esse valor, a desigualdade $A_{t}^{S} / L_{t}^{S} \geq \alpha$ torna-se verdadeira.

Vamos agora descrever os elementos algébricos que permitem determinar o valor $Z_{t}^{S}$ a ser cobrado dos participantes e patrocinadores para a cobertura da insuficiência estabelecida anteriormente. Introduziremos dois novos elementos: (i) 
uma variável indicadora do evento desequilíbrio e (ii) uma variável que compute os desequilíbrios sucessivos.

A seguir, vamos apresentar e explicar cada trecho do código necessário para a determinação de $Z_{t}^{s}$. Antes de tudo, é preciso ter em mente que $Z_{t}^{s}$ deve satisfazer à seguinte desigualdade: $\left(A_{t}^{S}+Z_{t}^{S} \geq \alpha L_{t}^{S}\right)$. Em palavras, essa desigualdade indica o menor valor de $Z_{t}^{S}$ que reestabeleça a condição $A_{t}^{S} / L_{t}^{S} \geq \alpha$.

Considere o seguinte conjunto de desigualdades:

$$
\begin{aligned}
A_{t}^{S}-\alpha L_{t}^{S} & \geq-M u_{t}^{s}, \\
A_{t}^{S}-\alpha L_{t}^{s} & \leq M\left(1-u_{t}^{s}\right)-\frac{1}{M}, \\
u_{t}^{s} & \in\{0,1\} .
\end{aligned}
$$

Como $u_{t}$ pode apenas assumir valores 0 ou 1 , vamos verificar o que ocorre com as desigualdades (3.36) e (3.37) para cada uma das possibilidades a seguir.

- Se $u_{t}=0$, então, considerada a desigualdade (3.36), tem-se que ( $A_{t}^{S}-$ $\left.\alpha L_{t}^{S}\right) \geq 0$ e, considerada a desigualdade (3.37), $\left(A_{t}^{S}-\alpha L_{t}^{S}\right) \leq M-1 / M$.

- Se $u_{t}=1$, então, considerada a desigualdade (3.36), tem-se que ( $A_{t}^{S}-$ $\left.\alpha L_{t}^{S}\right) \geq-M$ e, considerada a desigualdade (3.37), $\left(A_{t}^{S}-\alpha L_{t}^{S}\right) \leq-1 / M$.

Considerando o que acabamos de expor, podemos criar um quadro resumo indicando os intervalos a que pertencem $\left(A_{t}^{S}-\alpha L_{t}^{S}\right)$ para cada valor de $u_{t}$ considerado. Observe que, até este momento, conseguimos estabelecer um fato dado um valor de $u_{t}$. No entanto, a condição que precisamos estabelecer é: dado o fato, que valor $u_{t}$ deverá assumir. Em linguagem matemática, estamos buscando a forma contrapositiva da sentença obtida. Antes de chegar a isso, vamos resumir nossas conclusões:

$$
A_{t}^{S}-\alpha L_{t}^{S} \in \begin{cases}{[0, M-1 / M],} & \text { se } u_{t}=0 \\ {[-M,-1 / M],} & \text { se } u_{t}=1\end{cases}
$$


A forma contrapositiva da sentença "se $\mathbf{P}$, então $\mathbf{Q}$ " é dada por "se não Q, então não P". Agora estamos em condições de estabelecer a sentença desejada, forma contrapositiva da sentença anterior, para a indicação do valor de $u_{t}^{s}$. Como $M$ é um número muito grande (big $\mathrm{M}$ ), podemos descrever o valor de $u_{t}^{s}$ conforme indicado a seguir:

$$
u_{t}^{s}=\left\{\begin{array}{l}
0, \quad \text { se } A_{t}^{s}-\alpha L_{t}^{s} \geq 0 \\
1, \quad \text { se } A_{t}^{s}-\alpha L_{t}^{s}<0 .
\end{array}\right.
$$

Com isso, mostramos que podemos usar $u_{t}^{s}$ como variável indicadora do evento $A_{t}^{S}-\alpha L_{t}^{S}<0$. Sempre que isso ocorrer, ou, equivalentemente, sempre que $A_{t}^{S} / L_{t}^{S}<\alpha$, o valor de $u_{t}^{S}$ será igual a 1 . Essa é a primeira variável binária necessária para a contagem de eventos. Agora vamos estruturar uma segunda variável binária $-z_{t}^{S}-$ cuja função será indicar quando $u_{t}^{S}$ assumir o valor 1 a vezes consecutivas. A contagem do número de desequilíbrios será efetuada pelo seguinte conjunto de desigualdades:

$$
\begin{aligned}
z_{t}^{s} & \geq \sum_{i=t-a+1}^{t} u_{i}^{s}-a+1, \\
z_{t}^{s} & \leq u_{t}^{s} \\
u_{t}^{s}, z_{t}^{s} & \in\{0,1\} .
\end{aligned}
$$

Vamos agora entender o conjunto de desigualdades (3.39), (3.40) e (3.41).

1. Caso 1: Até o ano $t$ foram observados exatamente a desequilíbrios. Nesse caso, $u_{t}^{s}=1$ (lembre-se de que, se $A_{t}^{s}-\alpha L_{t}^{S}<0$, então $u_{t}^{s}=1$ ). Com isso, considerando tanto (3.39) quanto (3.40), $z_{t}^{s}$ assumirá o valor 1.

2. Caso 2: Até o ano $t$ foram observados menos do que a desequilíbrios. Nesse caso, considerada a desigualdade (3.73), $z_{t}^{s}$ tanto pode assumir o valor 0 como o valor 1. Contudo, considerada a desigualdade (3.40), duas hipóteses devem ser levadas em conta:

- se $u_{t}^{s}=0$, então $z_{t}^{s}$ também será 0 ;

- se $u_{t}^{s}=1$, então $z_{t}^{S}$ tanto pode assumir o valor 0 como o valor 1 , permanecendo, portanto, indeterminado. 
Em resumo, temos que, se $\sum_{i=t-a+1}^{t} u_{t}^{S}-a+1$ for igual a 1 , então $z_{t}^{S}$ também será igual a 1 ; se $\sum_{i=t-a+1}^{t} u_{t}^{s}-a+1$ for menor do que $1, z_{t}^{s}$ será nulo apenas se $u_{t}^{s}$ também o for, caso contrário, poderá assumir o valor 0 ou 1 .

Uma vez que (i) identificamos o sinal de $A_{t}^{S}-\alpha L_{t}^{S}$ e (ii) contamos o número de ocorrências de desequilíbrios até o ano $t$, podemos agora determinar o menor valor a ser cobrado de participantes e patrocinadores para o reestabelecimento do equilíbrio atuarial. Esse valor será representado por $Z_{t}^{s}$. Para tal, consideraremos as desigualdades:

$$
\begin{aligned}
& Z_{t}^{s} \leq M z_{t}^{s} \\
& Z_{t}^{s} \geq\left(\alpha L_{t}^{s}-A_{t}^{s}\right)-M\left(1-z_{t}^{s}\right), \\
& Z_{t}^{s} \geq 0 \\
& z_{t}^{s} \in\{0,1\} .
\end{aligned}
$$

Vamos recordar que, caso tenham ocorrido exatamente a desequilíbrios, $z_{t}^{S}$ assumirá o valor 1. Nesse caso, considerando as desigualdades (3.42) e (3.43), $\left(\alpha L_{t}^{S}-A_{t}^{S}\right) \leq Z_{t}^{S} \leq M$ e, por se tratar de um problema de minimização, $Z_{t}^{S}$ será feito igual a $\left(\alpha L_{t}^{S}-A_{t}^{S}\right)$. Por outro lado, caso até o ano $t$ tenham sido observados menos do que a desequilíbrios, $Z_{t}^{s}$ assumirá o valor correto, isto é, igual a 0 apenas se $u_{t}^{s}$ também for nulo. Caso contrário, $Z_{t}^{s}$ assumirá o valor incorreto $\left(\alpha L_{t}^{S}-A_{t}^{S}\right)$, mesmo com a ocorrência de menos do que a desequilíbrios consecutivos. Esse inconveniente pode ser contornado fazendo com que figure na função objetivo do problema de minimização um múltiplo positivo de $Z_{t}^{s}$ que torne "mais barato" onerar a contribuição normal do que a contribuição extraordinária.

Antes de iniciar a descrição do tema Devolução de Contribuição, vamos recapitular como modelamos a situação em que uma Contribuição Extraordinária é devida por participantes e patrocinadores.

1. Passo 1: criar uma variável binária indicadora para determinar a ocorrência de desequilíbrios.

2. Passo 2: criar uma outra variável binária indicadora para contar o número de desequilíbrios consecutivos. 
3. Passo 3: determinar o valor a ser cobrado de participantes e patrocinadores para devolver ao fundo de pensão sua condição de equilíbrio.

Esses três passos são gerais e podem ser utilizados em situações semelhantes. Em nosso caso, eles serão usados para modelar o desequilíbrio provocado quando é verificada a ocorrência de um superávit elevado e persistente.

\section{2 .3}

\section{Devolução de contribuição}

Agora será modelada a situação em que o fundo de pensão, como consequência de variações de ativo e passivo desiguais, apresente um ativo total superior ao passivo dos participantes. Nossa abordagem será mais abrangente do que a simples constatação da ocorrência de um superávit. Estudaremos a possibilidade de que a repetição de valores da relação $A_{t}^{S} / L_{t}^{S}$ acima de um valor previamente especificado pelo gestor possa conduzir a uma condição de superávit. Nosso interesse recai sobre a seguinte desigualdade:

$$
A_{t}^{S} / L_{t}^{S}>\beta
$$

A relação (3.46) corresponde à condição na qual se verifica que $A_{t}^{S}-$ $\beta L_{t}^{s}>0$, o que, em palavras, significa que o ativo do fundo de pensão é $\beta$ vezes superior ao seu passivo, onde $\beta$ é um número real maior do que a unidade. Quando essa situação de desequilíbrio ocorre repetidas vezes, significa que os ativos investidos experimentaram uma valorização excepcional; o passivo foi mal dimensionado, levando à cobrança de uma contribuição excessiva; ou ambos os fatos ocorreram simultaneamente. Qualquer que seja a origem do desequilíbrio, a legislação brasileira ${ }^{1}$ exige que, caso o ativo do fundo de pensão seja 1,25 vezes superior ao seu passivo por três anos consecutivos, parte desse excesso deve ser devolvido aos participantes e assistidos ou os benefícios do plano deverão ser ampliados. A legislação é, no entanto, bastante prudente ao exigir que, antes de devolver contribuições, seja verificado se o passivo do fundo de pensão foi

\footnotetext{
${ }^{1}$ Esse tema está disposto no Título III da Resolução CGPC n ${ }^{9}$ 26, de 29 de setembro de 2008.
} 
dimensionado considerando bases demográficas adequadas e taxas de desconto atuarial compatíveis com a realidade macroeconômica vigente. Enquanto essas duas condições não forem atendidas não é permitido ao gestor devolver excessos contributivos aos participantes. Feitas essas considerações, podemos agora avançar na formulação matemática do problema.

É importante notar que o problema de Devolução de Contribuição é essencialmente idêntico ao (já estruturado) problema da necessidade de realização de Contribuição Extraordinária. Existe apenas uma diferença entre eles: enquanto o primeiro implica uma redução das contribuições, o segundo corresponde a um aumento de seu valor. No entanto, sob a perspectiva da modelagem matemática, esses dois problemas são semelhantes.

O caminho a ser trilhado para a solução desse "novo" problema será o mesmo. Para tal, vamos seguir os passos 1, 2 e 3, indicados no final da seção anterior.

Primeiro devemos criar uma variável indicadora do evento $A_{t}^{S}-\beta L_{t}^{S}>0$. Isso vai exigir a criação de uma variável $o_{t}^{s}$ que pode assumir apenas valor igual à 0 ou 1. Conforme indicado anteriormente, devemos estabelecer as seguintes relações: se $A_{t}^{S}-\beta L_{t}^{S}>0$, então $o_{t}^{S}=1 \mathrm{e}$, se $A_{t}^{S}-\beta L_{t}^{S} \leq 0$, então $o_{t}^{S}=0$. Vimos também que essa forma final é obtida pela forma contrapositiva da sentença original. As desigualdades indicadas a seguir explicitam essa afirmação.

$$
\begin{aligned}
A_{t}^{S}-\beta L_{t}^{S} & \leq M o_{t}^{S} \\
A_{t}^{S}-\beta L_{t}^{S} & \geq \frac{1}{M}-M\left(1-o_{t}^{S}\right), \\
o_{t}^{S} & \in\{0,1\} .
\end{aligned}
$$

Vamos analisar as inequações (3.47) e (3.48). Se $o_{t}^{S}=0$, então $A_{t}^{S}-$ $\beta L_{t}^{S} \in[-M+1 / M, 0]$. Se $o_{t}^{S}=1$, então $A_{t}^{S}-\beta L_{t}^{S} \in[1 / M, M]$. A forma contrapositiva dessas inequações conduz ao resultado desejado:

$$
\begin{aligned}
& A_{t}^{S}-\beta L_{t}^{S}>0 \Rightarrow o_{t}^{S}=1 \\
& A_{t}^{S}-\beta L_{t}^{S} \leq 0 \Rightarrow o_{t}^{S}=0 .
\end{aligned}
$$

Devemos agora, a semelhança do problema anterior, contar o número de ocorrências da desigualdade $A_{t}^{S}-\beta L_{t}^{S}>0$. Esse problema é idêntico ao descrito 
pelas inequações (3.39), (3.40) e (3.41), com uma única alteração: a devolução de contribuição deve ser realizada caso o excesso patrimonial tenha sido observado ao longo de b anos consecutivos. As inequações necessárias são:

$$
\begin{aligned}
v_{t}^{S} & \geq \sum_{i=t-b+1}^{t} o_{i}^{S}-b+1, \\
v_{t}^{S} & \leq o_{t}^{s} \\
v_{t}^{S}, o_{t}^{S} & \in\{0,1\} .
\end{aligned}
$$

Por fim, devemos explicitar as desigualdades que determinarão o valor $V_{t}^{s}$ a ser devolvido aos participantes e patrocinadores.

$$
\begin{aligned}
& V_{t}^{s} \leq M v_{t}^{s}, \\
& V_{t}^{s} \geq\left(A_{t}^{s}-\beta L_{t}^{s}\right)-M\left(1-v_{t}^{s}\right), \\
& V_{t}^{s} \geq 0, \\
& v_{t}^{s} \in\{0,1\} .
\end{aligned}
$$

\subsection{4}

\section{A função objetivo do problema de minimização}

Agora já reunimos as condições necessárias para explicitar a função objetivo do problema a ser resolvido. Nosso interesse é determinar, no início de cada ano, a menor contribuição a ser paga por participantes e patrocinadores que mantenha o fundo de pensão em equilíbrio. Além da contribuição normal, também serão incluídos, na função objetivo, a devolução da contribuição e o pagamento de contribuição extraordinária, eventos que apenas ocorrerão em condições extremas, conforme indicado. Caso tais condições se verifiquem, as contribuições referidas deverão ser consideradas em seus valores mínimos para a restituição do equilíbrio do fundo de pensão.

O horizonte de planejamento se estende desde o ano $t=0$, que concentra todas as decisões anteriores ao momento em que o modelo de otimização é avaliado, até o ano $t=T$. No instante final do horizonte de planejamento, são 
determinados os valores presentes dos ativos e dos benefícios, considerando um horizonte de tempo ilimitado. A diferença entre ativo e passivo em $t=T$ é denominada solvência de longo prazo. O modelo se estende para um total de $S$ cenários macroeconometricamente consistentes. A seguir, descrevemos a função objetivo do problema de minimização que se deseja resolver.

$\sum_{s=1}^{S}\left[\sum_{t=0}^{T} p_{t}^{S} \gamma_{t}\left(c_{t}^{S} W_{t}^{S}+Z_{t}^{S}-\delta A_{t}^{S}\right)\right.$

funding/riqueza

PENALIZAÇÕES

$+\sum_{t=1}^{T} p_{t}^{S} \gamma_{t}\left[\zeta_{c i}\left(c_{t}^{s}-c_{t-1}^{s}-\rho\right)^{+}+\zeta_{c d}\left(c_{t-1}^{s}-c_{t}^{S}-\eta\right)^{+}\right] W_{t}^{s} \quad \begin{aligned} & \text { variação da taxa } \\ & \text { de contribuição }\end{aligned}$

\section{CONTRIBUIÇÃo EXTRAORDINÁRIA E DEVOLUÇÃo DE CONTRIBUIÇÃO}

$+\sum_{t=0}^{T} p_{t}^{S} \gamma_{t}\left(\zeta_{Z}-1\right) Z_{t}^{S}$

$+\sum_{t=0}^{T} p_{t}^{S} \gamma_{t} \zeta_{V} V_{t}^{S}$

CONDIÇÃO DE SOLVÊNCIA DE LONGO PRAZO

$\left.+p_{T}^{S} \gamma_{T}\left[\zeta_{\Lambda}\left(A_{T}^{S}-\Lambda L_{T}^{S}\right)^{-}+\zeta_{\Lambda i}\left(A_{T}^{S}-\Lambda L_{T}^{S}\right)^{+}\right]\right]$ contribuição

extraordinária

devolução de contribuição

A condição de solvência de longo prazo vai exigir duas condições adicionais: a soma de $\zeta_{\Lambda d}$ e $\zeta_{\Lambda i}$ deve ser positiva (essa condição é necessária para garantir convexidade) e $\zeta_{\Lambda i} \leq 0$ (essa imposição garante que $\left(A_{T}^{S}-\Lambda L_{T}^{S}\right)$ assuma o maior valor possível).

As condições que caracterizam a variação na taxa de contribuição e a solvência de longo prazo dificultam o tratamento do problema como um problema de otimização linear. Essa dificuldade será contornada conforme indicado a seguir. 
Vamos considerar que condições do tipo $q_{1}(f(x)-g(x))^{+}+$ $q_{2}(f(x)-g(x))^{-}$sejam introduzidas na função objetivo. Em uma análise superficial, parece que devemos utilizar uma variável indicadora para avaliar o sinal de $f(x)-g(x)$. Para evitar esse ônus computacional, é necessário criar duas variáveis de decisão, $\lambda_{1}(x)$ e $\lambda_{2}(x)$, ambas maiores ou iguais a 0 , e introduzir na função objetivo a seguinte parcela: $q_{1} \lambda_{1}(x)+q_{2} \lambda_{2}(x)$. Além disso, duas novas restrições devem ser adicionadas: $\lambda_{1}(x) \geq f(x)-g(x)$ e, $\lambda_{2}(x) \geq g(x)-f(x)$.

1. Caso $q_{1}(f(x)-g(x))^{+}$: Essa forma funcional apenas assumirá valor diferente de 0 quando $f(x)>g(x)$. Nesse caso, $\lambda_{1}(x)$ representa a folga na função $g(x)$ até que ela atinja o valor $f(x)$. Consequentemente, segue a desigualdade $\lambda_{1}(x)+g(x) \geq f(x)$. Essa condição, juntamente com a condição de não-negatividade imposta a $\lambda_{1}(x)$, conduzem ao valor mínimo buscado na função objetivo.

2. Caso $q_{2}(f(x)-g(x))^{-}$: Essa forma funcional apenas assumirá valor diferente de 0 quando $f(x)<g(x)$. Nesse caso, $\lambda_{2}(x)$ representa a folga na função $f(x)$ até ela atinja o valor $g(x)$. Consequentemente, segue a desigualdade $\lambda_{2}(x)+f(x) \geq g(x)$. Essa condição, juntamente com a condição de não-negatividade imposta a $\lambda_{2}(x)$, conduzem ao valor mínimo buscado na função objetivo.

Vamos impor uma última condição para evitar que o problema de minimização seja ilimitado. Suponhamos que $(f(x)-g(x))^{+}$e $(f(x)-g(x))^{-}$ sejam limitadas superiormente por $H(x)$. Desse modo, a soma $q_{1}(f(x)-$ $g(x))^{+}+q_{2}(f(x)-g(x))^{-}$é limitada superiormente por $\left(q_{1}+q_{2}\right) H(x)$. Sendo $H(x)$ positivo, a condição $q_{1}+q_{2}>0$ evita que o problema de minimização apresente solução ilimitada.

Antes de apresentar as restrições do problema, é importante ressaltar que as constantes $\zeta_{c i}, \zeta_{c d}, \zeta_{Z}, \zeta_{V}, \rho, \eta, \Lambda, \zeta_{\Lambda d}, \zeta_{\Lambda i}$ devem ser indicadas pelo gestor do fundo de pensão. Ao fazê-lo, ele deve ter em mente as condições que devem ser respeitadas para que o problema formulado faça sentido. 
$\zeta_{c i}$ - custo associado ao aumento da taxa de contribuição em dois anos consecutivos por valor maior do que $\rho$.

$\zeta_{c d}$ - custo associado à redução da taxa de contribuição em dois anos consecutivos por valor maior do que $\eta$.

$\zeta_{Z}$ - custo associado à necessidade de cobrar uma contribuição extraordinária em caso de déficit extremo e persistente.

$\zeta_{V}$ - custo associado à necessidade de restituir contribuição aos participantes em caso de superávit extremo e persistente.

$\rho$ - aumento máximo permitido para a taxa de contribuição em dois anos consecutivos sem que nenhuma penalização seja introduzida.

$\eta$ - decréscimo máximo permitido para a taxa de contribuição em dois anos consecutivos sem que nenhuma penalização seja introduzida.

$\Lambda$ - menor valor para o índice de solvência desejado para o fundo no ano limite do estudo.

$\zeta_{\Lambda d}$ - custo associado à verificação de um índice de solvência menor do que $\Lambda$ no ano limite do estudo.

$\zeta_{\Lambda i}-$ custo associado à verificação de um índice de solvência maior do que $\Lambda$ no ano limite do estudo.

Além de indicar o valor desses parâmetros, as seguintes relações devem ser atendidas:

$$
\begin{gathered}
\zeta_{c i} \geq \zeta_{c d} \\
\zeta_{c i}+\zeta_{c d}>0, \\
\zeta_{Z}>1 \\
\zeta_{V} \leq 0 \\
\Lambda \geq 1 \\
\zeta_{\Lambda i} \leq 0 \\
\zeta_{\Lambda i}+\zeta_{\Lambda d}>0 .
\end{gathered}
$$

Por fim, devemos comentar que a função objetivo apresentada anteriormente encontra-se ainda em sua versão original. Quando o problema for efetivamente resolvido, as relações do tipo $q_{1}(f(x)-g(x))^{+}+q_{2}(f(x)-$ 
$g(x))^{-}$deverão ser substituídas na função objetivo e as restrições correspondentes, introduzidas no problema a ser resolvido.

\subsection{5}

\section{O conjunto de restrições}

Nesta seção, explicitaremos o conjunto de restrições que deverão ser consideradas na determinação da contribuição a ser paga por participantes e patrocinadores. Além das receitas previdenciárias, as receitas de investimento também devem encontrar seus valores máximos, uma vez que é da natureza intrínseca dos fundos de benefícios definidos que, a partir de algum momento, as receitas de contribuição sejam insuficientes para o pagamento dos benefícios. Como nossa abordagem é orientada para problemas de ALM, ativos e passivos serão considerados conjuntamente.

Os ativos considerados neste trabalho são aqueles indicados na Resolução CMN n 3.792, de 24 de setembro de 2009, que, conforme a legislação, são classificados nos seguintes segmentos: renda fixa, renda variável, imóveis e operações com participantes (empréstimos e financiamentos concedidos aos participantes do fundo de pensão). Cada ativo integrante dos segmentos apresenta sua própria dinâmica, que será explicitada a seguir. O problema aqui posto pode ser classificado como um problema de ALM estratégico, em contraposição ao problema de ALM tático. No ALM estratégico, o gestor se preocupa com a alocação de recursos nos segmentos de investimentos permitidos por lei. Nesse tipo de problema, não há a preocupação com o ativo específico dentro de cada segmento. Dito de outra forma, no problema de ALM estratégico, a preocupação do gestor é determinar quanto deve ser investido ou desinvestido no segmento de ações, sendo imaterial a determinação da ação específica a ser transacionada. Parece óbvio que a saída de um problema de ALM estratégico deva servir de insumo para estabelecer cada carteira dentro de cada segmento. Isso, no entanto, não é objeto deste trabalho.

Serão considerados cinco tipos diferentes de ativos de renda fixa: caixa, títulos prefixados, títulos pós-fixados, além de dois outros ativos de renda fixa com padrão de volatilidade mais elevada. Adicionalmente, serão introduzidos ativos de renda variável, ativos representativos de operações imobiliárias e ativos 
representativos de operações com participantes. Cada um deles será modelado considerando sua dinâmica específica e introduzido no modelo de otimização como uma árvore de cenários. Os elementos técnicos dessa abordagem serão considerados nas próximas seções deste trabalho.

Por hipótese, o gestor dos investimentos pode comprar ou vender livremente seus ativos, incorrendo, nesse caso, em despesas com pagamento de taxas e corretagens. A ele não são permitidas vendas a descoberto, e a quantidade permitida para cada ativo é restrita aos seus limites inferiores e superiores. $\mathrm{Na}$ sequência, serão apresentadas algumas identidades e restrições do problema de minimização.

- O total do ativo dos participantes e assistidos:

$$
A_{t}^{S}=\sum_{j=1}^{N}\left(1+r_{j, t}^{S}\right) X_{j, t}^{S}+c_{t}^{S} W_{t}^{S}-B_{t}^{S}
$$

A identidade (3.59) define o total do ativo dos participantes. Esse total é formado pelos ativos financeiros de propriedade do fundo de pensão acrescidos de suas devidas remunerações. A essa parcela, acrescente-se ainda o resultado previdencial constituído pela diferença entre as contribuições recebidas e os benefícios pagos aos assistidos.

\section{- Dinâmica dos ativos financeiros:}

$$
\begin{array}{ccc}
X_{j, t+1}^{S} & = & \left(1+r_{j, t}^{s}\right) X_{j, t}^{S}+X C_{j, t}^{S}-X V_{j, t}^{S}, \\
X C_{j, t}^{S} & \geq & 0, \\
X V_{j, t}^{S} & \geq & 0 .
\end{array}
$$

O total do ativo $j$ no ano $t+1$ é constituído pelo valor do referido ativo no ano $t$, acrescido da remuneração devida pela sua posse e das compras menos as vendas, ambas efetuadas no ano $t$. 
- Realocação dos ativos:

$$
\begin{aligned}
\sum_{j=1}^{N} X_{j, t+1}^{s}+ & V_{t}^{s}+\sum_{j=1}^{N} k_{j}\left(X C_{j, t}^{s}+X V_{j, t}^{s}\right)=A_{t}^{s}+Z_{t}^{s} \\
V_{t}^{s} & \geq 0, \\
Z_{t}^{s} & \geq 0 .
\end{aligned}
$$

A equação (3.63) representa a relação de equilíbrio entre fontes e destino de recursos. Por hipótese, ao final de cada exercício, os ativos financeiros podem ser livremente transacionados desde que respeitados os limites de aplicação. O lado direito da equação (3.63) representa as fontes de financiamento - total do ativo dos participantes e as contribuições extraordinárias -, enquanto o lado esquerdo representa o destino desses recursos - realocação dos ativos, devolução de contribuição e pagamento das despesas com comissões e corretagens devidas pelas compras e vendas de ativos financeiros. As variáveis de decisão $Z_{t}^{S}$ e $V_{t}^{S}$ representam, respectivamente, a contribuição extraordinária cobrada dos participantes e patrocinadores e a contribuição devolvida aos participantes.

\section{- Limites de alocação nos ativos financeiros:}

$$
\underline{f_{j}} \sum_{i=1}^{N} X_{i, t}^{s} \leq X_{j, t}^{s} \leq \overline{f_{j}} \sum_{i=1}^{N} X_{i, t}^{s},
$$

onde $f_{j}$ e $\overline{f_{j}}$ representam o menor e o maior percentual que pode ser alocado em cada ativo financeiro. Esses limites são estabelecidos pelos gestores do fundo de pensão, que devem, no entanto, respeitar as determinações impostas na Resolução CMN no 3.792, de 24 de setembro de 2009. Indiretamente, o limite superior permitido para alocação em cada ativo representa uma medida de aversão ao risco. 
- Contribuição normal:

$$
\begin{aligned}
\underline{c} & \leq c_{t}^{s} \leq \bar{c} \\
c i_{t}^{s} & \geq c_{t}^{s}-c_{t-1}^{s}-\rho, \\
c d_{t}^{S} & \geq c_{t-1}^{s}-c_{t}^{s}-\eta \\
c i_{t}^{s}, c d_{t}^{s} & \geq 0 .
\end{aligned}
$$

A desigualdade (3.67) indica os limites inferior e superior da taxa de contribuição. As duas desigualdades seguintes indicam as variações permitidas para a taxa de contribuição em dois períodos consecutivos. De fato, elas representam a versão algorítmica das funções $\left(c_{t}^{s}-c_{t-1}^{s}-\rho\right)^{+} \mathrm{e}\left(c_{t-1}^{s}-\right.$ $\left.c_{t}^{s}-\eta\right)^{+}$. O termo $\zeta_{c i} c i_{t}^{s}+\zeta_{c d} c d_{t}^{S}$ deverá ser incluído na função objetivo.

- Contribuição extraordinária:

$$
\begin{aligned}
A_{t}^{s}-\alpha L_{t}^{s} & \geq-M u_{t}^{s}, \\
A_{t}^{s}-\alpha L_{t}^{s} & \leq M\left(1-u_{t}^{s}\right)-\frac{1}{M}, \\
z_{t}^{s} & \geq \sum_{i=t-a+1}^{t} u_{i}^{s}-a+1, \\
z_{t}^{s} & \leq u_{t}^{s}, \\
Z_{t}^{s} & \leq M z_{t}^{s}, \\
Z_{t}^{s} & \geq\left(\alpha L_{t}^{s}-A_{t}^{s}\right)-M\left(1-z_{t}^{s}\right), \\
Z_{t}^{s} & \geq 0, \\
u_{t}^{s}, z_{t}^{s} & \in\{0,1\} .
\end{aligned}
$$

Esse conjunto de desigualdades determina o valor $Z_{t}^{S}$ da contribuição extraordinária a ser paga por participantes e patrocinadores caso seja verificada a ocorrência do evento $\left(A_{t}^{S}-\alpha L_{t}^{S}<0\right)$ durante a anos consecutivos. 
- Devolução de contribuição:

$$
\begin{aligned}
& \beta L_{t}^{S}-A_{t}^{S} \geq-M o_{t}^{S}, \\
& \beta L_{t}^{s}-A_{t}^{s} \leq M\left(1-o_{t}^{S}\right)-\frac{1}{M^{\prime}} \\
& v_{t}^{s} \geq \sum_{i=t-b+1}^{t} o_{i}^{s}-b+1, \\
& v_{t}^{s} \leq o_{t}^{s} \\
& V_{t}^{s} \leq M v_{t}^{s}, \\
& V_{t}^{s} \geq\left(A_{t}^{S}-\beta L_{t}^{S}\right)-M\left(1-v_{t}^{S}\right), \\
& V_{t}^{s} \geq 0 \text {, } \\
& v_{t}^{S}, o_{t}^{S} \in\{0,1\} \text {. }
\end{aligned}
$$

Esse conjunto de desigualdades determina o valor $V_{t}^{S}$ da contribuição extraordinária a ser paga por participantes e patrocinadores caso seja verificada a ocorrência do evento $\left(A_{t}^{S}-\beta L_{t}^{S}>0\right)$ durante b anos consecutivos. 


\section{Geração dos cenários}

Neste capítulo, descreveremos como devem ser gerados os cenários para o problema de otimização estocástica multiperíodo. É natural exigir que os cenários apresentem consistência com os dados históricos e com a teoria econômica. Além dessas duas condições pétrias, será ainda introduzida outra condição de ordem técnica que deve ser verificada: a condição de não-antecipacidade. Essa condição determina que, estando em um determinado nó na árvore de cenários, o valor da variável analisada deverá ser o mesmo para todos os cenários que puderem ser alcançados a partir daquele nó. Antes de avançarmos na descrição da técnica de geração dos cenários, vamos introduzir a notação $\left[b_{1}, b_{2}, \ldots, b_{T}\right]$ para representar a árvore de cenários. Nessa representação, o problema de otimização se desenvolve em $T$ períodos, e existe um total de $\prod_{i=1}^{T} b_{i}$ cenários possíveis. A transição de $t=0$ para $t=1$ é feita por $b_{1}$ diferentes trajetórias e, para cada uma dessas trajetórias, existem $b_{2}$ maneiras distintas de fazer a transição da época $t=1$ para a época $t=2$. Por fim, estando em $t=T-1$, para cada um dos nós existentes nessa época, poderão ser trilhadas $b_{T}$ trajetórias distintas com o intuito de alcançar as folhas da árvore. Computacionalmente, a estrutura $\left[b_{1}, b_{2}, \ldots, b_{T}\right]$ será transformada em uma matriz de cenários com $T$ linhas e $\prod_{i=1}^{T} b_{i}$ colunas cuja estrutura satisfaz a condição de não-antecipação. Por exemplo, uma árvore de cenários $[1,3,2]$ será representada por uma matriz $(\mathrm{TxS})$ contendo 3 linhas e 6 colunas com a seguinte forma:

$$
A=\left[\begin{array}{llllll}
a & a & a & a & a & a \\
b & b & c & c & d & d \\
e & f & g & h & i & j
\end{array}\right]
$$

Em $t=1$, representado pela primeira linha da matriz de cenários, é possível atingir todas as folhas da árvore. Isso é indicado pela composição da primeira linha da matriz A, cujos 6 elementos são idênticos. A transição para $t=2$, representado pela segunda linha da matriz A, se dá por três trajetórias 
distintas. De cada uma delas é possível atingir dois cenários distintos. Sendo assim, devemos preencher essa linha com 3 pares de elementos, sendo os elementos de cada par idênticos. Por fim, as folhas da árvore serão atingidas a partir do tempo $t=2$, o que leva à representação indicada na terceira linha da matriz A de cenários.

A anatomia da matriz $A$ estará presente nos cenários que servirão de entrada de dados, a saber, os salários dos participantes, os benefícios a serem pagos aos assistidos, o passivo atuarial e as rentabilidades dos ativos financeiros ${ }^{1}$. Neste trabalho, as três primeiras variáveis evoluíram ritmadas pelas variações da inflação estimada. Em um trabalho futuro, recomenda-se que essa evolução seja estimada levando em conta, além dos aspectos econômicos, também os demográficos. Após resolvido o problema de otimização objeto deste trabalho, as seguintes variáveis de decisão serão indicadas na mesma forma da matriz $A$ : taxa de contribuição de participantes e patrocinadores, contribuição a ser devolvida aos participantes, contribuição extraordinária a ser cobrada dos participantes e patrocinadores, valor da compra de ativos e valor da venda dos ativos ${ }^{2}$. Isso garante que as condições de não-antecipacidade, imposição do modelo multiestágio, estejam presentes no modelo de otimização.

\section{1}

\section{Os ativos financeiros}

Ao gestor dos investimentos será permitido alocar recursos em um total de oito ativos: cinco variações de renda fixa, renda variável, imóveis e empréstimos aos participantes ${ }^{3}$. Como um desses ativos são títulos pós-fixados, será necessária a inclusão de cenários que descrevam a dinâmica de algum índice de preços.

Parece natural tentar gerar os cenários estocásticos utilizando estimativas a partir de um modelo Vector AutoRegressive - VAR. Infelizmente, com os dados disponíveis, essa utilização pode conduzir a cenários inadequados. Qualquer estimativa econométrica séria deve considerar a ruptura estrutural introduzida

\footnotetext{
${ }^{1} \mathrm{Na}$ verdade, a rentabilidade dos ativos será introduzida por uma matriz tridimensional (TxSxN), onde $\mathrm{N}$ representa o número de ativos permitidos.

${ }^{2}$ Essas variáveis também serão apresentadas na forma de uma matriz (TxSxN).

${ }^{3}$ Em uma visão mais estratégica, podemos considerar apenas quatro ativos: renda fixa, renda variável, imóveis e empréstimos aos participantes
} 
com o advento do Plano Real (1994). Os processos característicos das séries econômicas antes desse período apresentam dinâmicas distintas e, portanto, não podem ser utilizados para estimação dos parâmetros do modelo VAR. Isso nos conduz a um total de menos de 20 anos de observações, o que torna não recomendável sugerir a utilização de modelos VAR caso se deseje trabalhar com cenários de periodicidade anual.

Feitas essas observações, passamos a descrever como os cenários serão gerados: algumas variáveis primárias serão fixadas e as variáveis de interesse serão obtidas a partir das relações econômicas existentes entre elas.

$\mathrm{Na}$ estruturação dos cenários, será utilizado um importante processo estocástico denominado Movimento Browniano, definido a seguir.

Definição 4.1.1 (Movimento Browniano unidimensional) Um Movimento Browniano unidimensional em $[0, T]$ é um processo estocástico $\{W(t), 0 \leq t \leq$ T\} com as seguintes propriedades:

1. $W(0)=0$;

2. O mapeamento $t \rightarrow W(t) e ́$, com probabilidade 1 , uma função contínua no intervalo $[0, T]$;

3. Os incrementos $\left\{W\left(t_{1}\right)-W\left(t_{0}\right), W\left(t_{2}\right)-W\left(t_{1}\right), \ldots, W\left(t_{\mathrm{k}}\right)-W\left(t_{\mathrm{k}-1}\right)\right\}$ são independentes de $k$;

4. $W(t)-W(s) \sim N(0, s-t)$ para todo $0 \leq s<t<T$.

O processo estocástico Movimento Browniano vai desempenhar um importante papel na simulação dos cenários estocásticos conforme veremos a seguir. Mais importante do que isso, ele pode ser gerado a partir de simulações de variáveis aleatórias normais com média zero e variância unitária, o que torna o processo de simulação mais simples. Isso pode ser feito conforme indicado a seguir.

Se $\left\{t_{0}=0, t_{1}, \ldots, t_{i}, t_{i+1}, \ldots, t_{N}=T\right\}$ representa uma partição do intervalo $[0, T]$, temos a seguinte aproximação:

$$
d W\left(t_{i}\right)=W\left(t_{i+1}\right)-W\left(t_{i}\right)=N\left(0, t_{i+1}-t_{i}\right)=\sqrt{t_{i+1}-t_{i}} Z_{i}
$$


onde $Z_{i}$ é um número aleatoriamente escolhido de uma distribuição normal com média 0 e variância 1. Essa discretização, devida a Euler, foi obtida considerando o item 4 na definição de Movimento Browniano. Nesse caso, a simulação de $d W\left(t_{i}\right)$ se reduz à capacidade de gerar variáveis aleatórias normais com média 0 e variância 1. A equação (4.1) vai desempenhar um papel destacado na simulação dos processos definidores das variáveis utilizadas no problema de otimização. Vamos agora descrever a dinâmica dos processos de interesse.

- Caixa:

$$
d r(t)=\alpha(b-r(t)) d t+\sigma \sqrt{r(t)} d W(t)
$$

Se $r(0)>0$ e $2 \alpha b \geq \sigma^{2}$, então $r(t)$, conforme definido em (4.2), nunca assumirá valor igual a 0 . Esse processo tem a propriedade de reversão à média. O parâmetro $\alpha$ representa a velocidade de reversão à média e $\sigma$ é a volatilidade do processo. Em [19], Paul Glasserman apresenta uma boa descrição da dinâmica de ativos de renda fixa.

- Títulos prefixados:

$$
r_{p r e}(t)=\frac{r(t-1)^{20-(t-1)}}{r(t)^{(20-t)}}-1
$$

onde $r(t)$ é um processo gerado conforme definido em (4.2). A dinâmica definida em (4.3) indica que os títulos prefixados considerados nesta modelagem têm maturidade de 20 anos. Títulos com tal maturidade são comuns nos portfólios dos fundos de pensão.

- Títulos pós-fixados:

$$
r_{p o s}(t)=(1+\Pi(t)) *(1+\vartheta)-1,
$$


onde $\Pi(t)$ representa a inflação corrente - que, neste trabalho, será gerada pelo processo cuja dinâmica é definido por (4.2) - e $\vartheta$ indica o ganho acima da inflação observada.

- Renda variável:

$$
\frac{d S(t)}{S(t)}=\left(\mu-\frac{1}{2} \sigma^{2}\right) d t+\sigma d W
$$

Nesse processo, também conhecido como Movimento Geométrico Browniano, o parâmetro $\mu$ é denominado drift do processo, $\sigma$ representa sua volatilidade e $d S(t) / S(t)$ corresponde à variação no preço do ativo. O drift e a volatilidade do processo deverão ser estimados.

- Imóveis

Em agosto de 2011, a Fundação Getúlio Vargas passou a apurar e divulgar o índice IGV-M, que mede a rentabilidade auferida pelos proprietários de imóveis. Os imóveis de interesse dos fundos de pensão apresentam as características dos imóveis incluídos na aferição do IGV-M. Nesse caso, a dinâmica definida em (4.2) representa um modelo adequado para o índice em apreço. Os parâmetros que identificam a reversão à média e a volatilidade deverão ser estimados.

- Empréstimos a participantes:

$$
o p(t)=(1+\Delta \operatorname{salario}(t)) *(1+\mathrm{Y})-1
$$

onde $\Delta$ salario $(t)$ representa a variação da massa salarial recebida pelos participantes e $\mathrm{Y}$ representa o ganho real indicado nos contratos de empréstimos com os participantes.

Antes de expor os demais processos que vão compor o modelo de otimização, descreveremos em detalhes como gerar realizações de um Movimento 
Browniano. Como exemplo, vamos considerar o processo descrito pela equação (4.5). Neste ponto, é necessária uma explicação adicional: como $\mathrm{S}(\mathrm{t})$ representa o preço do ativo de renda variável, o processo $d S(t) / S(t)$, indicado em (4.5) já representa o retorno do ativo entre os instantes $t_{i+1}$ e $t_{i}$. Portanto, a rentabilidade em $t_{i}$, que corresponde à variável de interesse no modelo apresentado, é dada por:

$$
r\left(t_{i}\right)=\left(\mu-\frac{1}{2} \sigma^{2}\right)\left(t_{i+1}-t_{i}\right)+\sigma \sqrt{t_{i+1}-t_{i}} Z\left(t_{i}\right)
$$

A equação (4.7) foi obtida a partir de (4.5) utilizando a equação (4.1). Os detalhes sobre a solução de equações diferenciais estocásticas podem ser obtidos em Øksendal [21] ou Korn e Korn [22]. Alguns dos processos anteriormente descritos devem ter os parâmetros que os descrevem previamente estimados. Aqui, mais uma vez, a dificuldade de estimação de parâmetros se manifesta. É importante lembrar que, caso se opte por trabalhar com dados anuais, a escassez de informações consistentes disponíveis dificulta consideravelmente alcançar esse objetivo. Sendo assim, além da estimação econométrica, recomenda-se também que especialistas avaliem as séries de interesse. Feitos os ajustamentos necessários, o modelo de otimização pode ser rodado para determinar as indicações ótimas sobre a macroalocação dos ativos no fundo de pensão.

Embora o movimento Browniano seja bastante utilizado para modelar ativos econômicos, é importante salientar que existem outras alternativas que poderiam ser utilizadas. Para saber mais, o leitor interessado pode consultar James, Jessica e Webber [4], por exemplo. Nessa obra, os autores discorrem sobre diversos modelos matemáticos utilizados para descrever a dinâmica da evolução temporal da taxa de juros. No entanto, tão importante quanto a determinação do modelo matemático para a descrição dos ativos relevantes para o problema é a geração de cenários em que a estrutura de correlação entre os ativos seja considerada. Esse, de fato, é um grande desafio: gerar cenários em árvore macroeconomicamente válidos que satisfaçam as condições de não-antecipação. 


\section{2}

\section{Os benefícios, a massa salarial e o passivo atuarial}

Vamos agora estabelecer os modelos estocásticos para o valor dos benefícios a serem pagos aos assistidos, o total da folha de salário dos participantes e o passivo atuarial dos beneficiários do plano. Neste trabalho, utilizaremos uma modelagem quase que ingênua sobre a dinâmica desses processos: por ora, vamos admitir que eles evoluam ritmados pela evolução da massa salarial praticada pelo patrocinador. Em uma evolução natural e mais sofisticada, deve-se avançar para a avaliação estocástica de cada um dos processos anteriormente descritos. Esse olhar mais sofisticado sobre o problema coloca-o no nível dos modelos de ALM estocástico. Na abordagem estocástica, o passivo dos participantes será explicitado em cada cenário como uma realização do processo estocástico que o define. No processo de avaliação atuarial estocástica - insumo para alimentar o modelo de ALM estocástico - há que se determinar a dinâmica da evolução da massa salarial dos participantes e a dinâmica dos benefícios a serem pagos aos assistidos. Se, por um lado, estocastizar o modelo de ALM pode trazer melhoras significativas na abordagem do problema; por outro, o esforço computacional aumenta consideravelmente. Não é claro, neste momento, que tal esforço justifique o ônus de envidar esforços na estruturação do processo de avaliação atuarial estocástica. $\mathrm{O}$ que podemos afirmar é que, independentemente de o fundo de pensão optar pela implementação de um modelo de ALM estocástico ou determinístico, deve-se investir no processo de avaliação atuarial estocástica. Esse é o mecanismo que permitirá ao gestor fazer afirmações de natureza probabilística sobre a verdadeira realidade atuarial que envolve o fundo de pensão. Também é importante frisar que, por mais rica e esclarecedora que seja uma avaliação atuarial estocástica, o plano de contas ao qual estão submetidos os fundos de pensão não admitem essa metodologia de avaliação atuarial. Neste trabalho, em vez de avaliar estocasticamente os benefícios prometidos, a evolução salarial dos participantes e o passivo atuarial - elementos fundamentais para proceder um modelo de ALM estocástico -, vamos apenas descrever dinâmicas estocásticas para cada um desses processos. Tais dinâmicas estão indicadas a seguir: 
- Os benefícios:

$$
B_{t+1}^{s}=B_{t}^{s}\left(1+\Delta \text { salario }_{t}^{S}\right) .
$$

- A massa salarial:

$$
W_{t+1}^{s}=W_{t}^{s}\left(1+\Delta \text { salario }_{t}^{s}\right) .
$$

- O passivo atuarial:

$$
L_{t+1}^{S}=L_{t}^{S}\left(1+\Delta \text { salario }_{t}^{S}\right) .
$$

Antes de encerrarmos esta seção, devemos tecer alguns comentários sobre a variação da massa salarial. Por hipótese, os salários dos participantes são corrigidos anualmente. Vamos admitir que a variação salarial anual contemple, além da variação de algum índice de preços, um aumento real. A variação do índice de preços tem o efeito de reposição do poder de compra dos salários; já o aumento real deve refletir toda uma política salarial nele contemplado; inclusive ganhos individuais oriundos de promoções e gratificações recebidas pelos trabalhadores. Vale lembrar que o índice de preços e o aumento real devem ser estatisticamente estimados. 


\section{5}

\section{Estudo de casos}

Neste capítulo, vamos elaborar dois exemplos nos quais será indicado como os gestores do fundo de pensão podem orientar a macroalocação dos ativos. É preciso lembrar que o modelo abordado nesta dissertação aplica-se a um fundo de pensão do tipo benefício definido, o que equivale dizer que os ajustes necessários serão efetuados na contribuição paga por participantes, assistidos e patrocinadores. Também é importante lembrar que estamos tratando do ALM estratégico, em que não distinguimos o ativo a ser transacionado. Dito de outra forma, quando o modelo de otimização indica, por exemplo, a compra de ativos de renda variável, não é possível identificar exatamente que ativo deve ser adquirido. Essa função será desempenhada em um segundo momento. Dividindo a gestão dos investimentos nos níveis estratégico, tático e operacional temos:

- Nível Estratégico: Atribuição exercida pelo Conselho Deliberativo do fundo de pensão. Cabe a ele, a partir dos cenários para as variáveis relevantes e para o horizonte de planejamento indicado, contratar um modelo de ALM estratégico. Como produto gerado por esse modelo, serão indicados, para cada um dos cenários considerados, a política ótima de contribuição e de macroalocação dos ativos. A política de contribuição envolve tanto a contribuição normal como as contribuições extraordinárias e eventuais devoluções de contribuição.

- Nível Tático: Atribuição exercida pelo Diretor de Investimentos do fundo de pensão. Neste nível, a política ótima de macroalocação para cada cenário já é conhecida. O Diretor de Investimentos deverá eleger o cenário que julga ter a maior probabilidade de ocorrência e, com as ferramentas à sua disposição, determinar os ativos a serem transacionados conforme indicado pelo modelo de ALM. Deve-se ter em mente que o modelo desenvolvido neste trabalho é um modelo multiperíodo. Isso significa que o cenário eleito se desdobra durante todos os anos do horizonte de planejamento. Assim, há 
que se produzir hoje decisões de investimento que serão implementadas nos próximos anos do período considerado.

- Nível Operacional: Atribuição exercida pelo Responsável pela Mesa de Operações do fundo de pensão. Neste nível, já foram definidas a macro e a microalocação dos ativos. Cabe agora determinar o momento ideal de implementar tais decisões de investimentos. Os cenários usados no modelo indicam rentabilidades esperadas para cada um dos ativos considerados. Como resposta, o modelo determina o percentual a ser alocado em cada segmento permitido. Compete ao operador alocar os valores indicados tentando obter rentabilidades superiores àquelas indicadas no cenário considerado. Caso seja bem-sucedido, aquele segmento de aplicação contribuirá, coeteris paribus, para uma geração de resultados superior à previamente indicada pelo modelo de ALM.

Ao final de cada ano, os parâmetros e cenários serão reavaliados, o modelo de ALM deverá ser rodado novamente e os ajustes impostos pelos desvios entre o cenário fixado e o cenário observado deverão ser realizados. Nesse momento, cada desvio deve ser cuidadosamente analisado e as causas de sua ocorrência devem ser determinadas. Essa é uma disciplina necessária, uma vez que estamos lidando com um modelo multiperíodo e os desvios observados podem se propagar, potencializando resultados bons ou ruins. É possível também que, apesar dos melhores esforços na fixação dos cenários, alguma descontinuidade se configure. Em 1994, por exemplo, a promulgação do Plano Real obrigou que todos os cenários fossem refeitos e, naquela ocasião, todo o esforço de precificação de ativos exigiu novos conhecimentos e produziu outros valores. Recentemente, a crise mundial de 2008 também exigiu dos analistas a redefinição de seus cenários de longo prazo.

\section{1}

\section{Primeiro exemplo: Necessidade de contribuição extraordinária}

Vamos avaliar algumas possibilidades para o caso de haver a necessidade de recursos que não possa ser suprida apenas com a contribuição normal. Este exemplo foi especialmente preparado para evidenciar tal necessidade. Em outras 
palavras, os cenários elaborados podem não representar exatamente a realidade atual, todavia permitem aclarar a situação que desejamos enfatizar. No exemplo, a contribuição normal paga por participantes e patrocinadores, que permitimos variar entre $10 \%$ e $20 \%$ do total da folha de salário dos participantes ativos, foi estabelecida como parâmetro. Além disso, os parâmetros $\alpha$ e $\beta$ foram fixados em 1,10 e 1,20, já $a$ e $b$ foram ambos fixados em 3 anos. Isto é, sempre que a relação $A_{t}^{S} / L_{t}^{S}$ for menor do que 1,10 por três anos consecutivos, participantes e patrocinadores deverão um valor $Z_{t}^{S}$ como contribuição extraordinária; caso $A_{t}^{S} / L_{t}^{S}$ seja maior do que 1,20 por mais de 3 anos consecutivos, um valor $V_{t}^{s}$ terá que ser devolvido aos participantes. Neste primeiro exemplo, foi considerada a árvore binária com a seguinte forma: $[1,2,2,2,2,2]$. Essa árvore se desenvolve em 6 períodos e tem um total de 32 cenários possíveis. Na tabela a seguir, estão sumarizados os valores ótimos de algumas variáveis ou funções destas, determinados no problema de otimização.

Tabela 5.1: Valores ótimos obtidos considerando o cenário 29

\begin{tabular}{|c|c|c|c|c|}
\hline $\begin{array}{l}\text { TEMPO } \\
\text { EM ANOS }\end{array}$ & $\begin{array}{l}\text { CONTRIBUIÇÃO } \\
\text { NORMAL INCIDENTE } \\
\text { SOBRE O SALÁRIO }\end{array}$ & $\begin{array}{c}A_{t}^{s} / L_{t}^{s} \\
\text { ANTES DE } Z_{t}^{s}\end{array}$ & $\begin{array}{c}\text { CONTRIBUIÇÃO } \\
\text { EXTRAORDINÁRIA } \\
Z_{t}^{s} \text { EM } R \$ \text { MIL }\end{array}$ & $\begin{array}{c}A_{t}^{S} / L_{t}^{S} \\
\text { DEPOIS DE } Z_{t}^{S}\end{array}$ \\
\hline 1 & $10,00 \%$ & 0,9470 & $1.265,8$ & 1,1000 \\
\hline 2 & $11,50 \%$ & 1,1195 & - & 1,1195 \\
\hline 3 & $11,14 \%$ & 0,5734 & $4.595,7$ & 1,1000 \\
\hline 4 & $12,64 \%$ & 1,2363 & - & 1,2363 \\
\hline 5 & $12,04 \%$ & 1,1063 & - & 1,1063 \\
\hline 6 & $10,00 \%$ & 1,0115 & - & 1.0115 \\
\hline
\end{tabular}

A Tabela 5.1 evidencia alguns fatos importantes, que vamos relatar na sequência. Apenas nos anos 1 e 3 houve a necessidade de cobrar de participantes e patrocinadores uma contribuição extraordinária. Nesses anos, caso se optasse por suportar a demanda por recursos recorrendo apenas à contribuição normal, esta teria sido, respectivamente, de $87,18 \%$ e $213,52 \%$ do total da folha de salário. Considerada a magnitude desses valores, dificilmente as partes envolvidas suportariam tais encargos. Outra alternativa para retornar o fundo de pensão à situação de equilíbrio consiste em buscar os recursos necessários $Z_{t}^{S}$ pela via dos investimentos. Essa alternativa exigiria que o gestor obtivesse uma rentabilidade 
de $16,15 \%$ e $69,95 \%$ no primeiro e no terceiro ano de administração. Essas rentabilidades também são excessivas, principalmente se considerarmos que, admitidas as restrições de alocação impostas, a maior rentabilidade possível para o cenário em estudo são de 16,57\% e 17,86\% nos anos 1 e 3 respectivamente. Fica claro, então, que reconduzir a relação $A_{t}^{s} / L_{t}^{S}$ para níveis superiores a 1,10 apenas com recursos de investimentos pode levar o gestor do fundo de pensão a assumir um risco excessivo, incompatível com o perfil conservador dessa classe de investidores. Nesse caso, recomendamos que o gestor do fundo reexamine os parâmetros que dificultam a obtenção do valor desejado para a razão entre ativo e passivo. Por oportuno, ele deve ainda avaliar se 1,10 para essa razão é exequível ou se esse indicador pode ser reduzido.

Vamos agora mostrar a proposta de macroalocação recomendada pelo modelo de otimização. Antes, porém, vale lembrar que os recursos serão distribuídos respeitando os limites de alocação impostos, as rentabilidades esperadas dos ativos e a necessidade de gerar recursos suficientes para o pagamento dos benefícios contratados e custear as demais despesas operacionais. No exemplo em estudo, foram admitidos os seguintes limites superiores para a alocação de recursos: renda fixa, 100\%; renda variável, 50\%; imóveis, 11\%; e operações com participantes, 8\%. Os limites inferiores para a aplicação de recursos foram fixados em 0 , exceto o limite do ativo renda variável, para o qual foi estabelecido um limite de 3\%. A tabela a seguir mostra as rentabilidades esperadas, indicadas na árvore de cenários, considerando o cenário 29.

Tabela 5.2: Retorno dos ativos - cenário 29 expresso em \% ao ano

\begin{tabular}{l|r|r|r|r|r|r}
\hline ATIVOS & ANO 1 & ANO 2 & ANO 3 & ANO 4 & ANO 5 & ANO 6 \\
\hline \hline Renda Fixa & 9,00 & 6,77 & 5,96 & 6,90 & 6,51 & 7,91 \\
\hline Renda Variável & 2,19 & 11,60 & 5,38 & 4,71 & 6,81 & 1,22 \\
\hline Imóveis & 11,83 & 11,45 & 13,19 & 10,98 & 10,61 & 8,50 \\
\hline Operações com Participantes & 17,15 & 16,76 & 18,58 & 16,27 & 15,87 & 13,67 \\
\hline \hline
\end{tabular}

$\mathrm{Na}$ Tabela 5.2, os valores grafados em vermelho representam rentabilidades esperadas menores do que 0 .

O fundo de pensão caracterizado neste modelo, no período considerado, apresenta despesa previdenciária superior à sua receita, também previdenciária. Em números, a diferença negativa entre as contribuições recebidas e os benefícios 
pagos são: 343,$2 ; 372,1 ; 449,4 ; 483,0 ; 577,8$; e 727,8 milhares de reais entre os anos 1 e 6. Nesse caso, cabe ao gestor dos investimentos do fundo de pensão formular estratégias capazes de garantir a liquidez necessária para o provimento das despesas com o pagamento dos benefícios. Além da despesa previdenciária, as despesas com investimentos, materializada na cobrança de taxas de comissões e corretagens incidentes sobre a movimentação dos ativos financeiros (compras e vendas), também deverão ser cobertas pela receita gerada pelos investimentos. A tabela a seguir apresenta as compras e vendas efetuadas, base para incidência do pagamento de comissões e corretagens.

Tabela 5.3: Compras e vendas de ativos - cenário 29 expresso em milhões de Reais

\begin{tabular}{l|r|r|r|r|r}
\hline ATIVOS & \multicolumn{1}{|c|}{ ANO 1 } & \multicolumn{1}{c|}{ ANO 2 } & \multicolumn{1}{c|}{ ANO 3 } & \multicolumn{1}{c|}{ ANO 4 } & \multicolumn{1}{c}{ ANO 5 } \\
\hline \hline Renda Fixa & $1.429,7$ & 274,6 & $3.194,9$ & 0,0 & 511,1 \\
\hline Renda Variável & 612,6 & 22,0 & 527,5 & 379,8 & 51,8 \\
\hline Imóveis & 84,1 & 79,1 & 382,9 & 108,0 & 125,4 \\
\hline Operações com Participantes & 0,0 & 0,0 & 0,0 & 0,0 & 0,0 \\
\hline \hline Saldo das Operações & 901,2 & 375,8 & $4.105,3$ & 487,8 & 584,7 \\
\hline
\end{tabular}

$\mathrm{Na}$ Tabela 5.3, os valores grafados em preto se referem a compras de ativos, enquanto os grafados em vermelho indicam os valores das vendas de ativos. A linha Saldo das Operações, que é numericamente igual à soma algébrica do valor das compras subtraído o valor das vendas, também equivale ao total das contribuições recebidas menos as contribuições devolvidas aos participantes e assistidos, as despesas com o pagamento dos benefícios e as despesas com o pagamento de comissões e corretagens. Tomando como exemplo os anos 1 e 2, temos: (i) no ano 1, a receita de contribuição normal e extraordinária totalizou 922,5 milhões de Reais, que subtraídos os 21,3 milhões de reais gastos com o pagamento de despesas, comissões e corretagens totalizam 901,2 milhões de Reais, conforme indicado na primeira coluna da Tabela 5.3; (ii) já no ano 2, foram consumidos 372,0 milhões de Reais que, adicionados às contribuições normais, foram necessários para o pagamento dos benefícios devidos aos assistidos. Nesse mesmo ano, foram consumidos ainda 3,8 milhões de Reais com o pagamento de comissões e corretagens, totalizando 375,8 milhões de Reais, conforme disposto na segunda coluna da Tabela 5.3. 
Uma vez conhecidas as rentabilidades esperadas dos ativos, indicadas na Tabela 5.2, e a política de compras e vendas de ativos, descrita na Tabela 5.3, podemos indicar a distribuição dos ativos ao longo dos anos que compõem o horizonte de planejamento. Essa distribuição pode ser vista na Tabela 5.4.

Tabela 5.4: Total investido - cenário 29 expresso em milhões de Reais

\begin{tabular}{l|r|r|r|r|r|r}
\hline ATIVOS & \multicolumn{1}{|c|}{ ANO 1 } & \multicolumn{1}{c|}{ ANO 2 } & \multicolumn{1}{c|}{ ANO 3 } & \multicolumn{1}{c|}{ ANO 4 } & \multicolumn{1}{c|}{ ANO 5 } & \multicolumn{1}{c}{ ANO 6 } \\
\hline \hline Renda Fixa & $6.181,0$ & $8.167,0$ & $8.445,0$ & $12.143,0$ & $12.981,0$ & $13.315,0$ \\
\hline Renda Variável & 943,7 & 310,4 & 324,4 & 834,5 & 493,90 & 512,2 \\
\hline Imóveis & 942,6 & $1.138,2$ & $1.189,5$ & $1.729,2$ & $1.811,1$ & $1.877,8$ \\
\hline $\begin{array}{l}\text { Operações com } \\
\text { Participantes }\end{array}$ & 625,0 & 732,1 & 854,9 & $1.013,7$ & $1.178,6$ & $1.365,7$ \\
\hline \hline Total Investido & $8.692,3$ & $10.347,8$ & $10.813,8$ & $15.720,4$ & $16.464,6$ & $17.070,7$ \\
\hline
\end{tabular}

Os elementos da Tabela 5.3 representam a base para a alocação tática dos recursos garantidores das provisões matemáticas. É importante lembrar que nosso propósito é solucionar um problema de ALM estratégico. Nesse caso, a estruturação das carteiras a partir dos quatro segmentos considerados é feita posteriormente levando em conta as recomendações contidas na Tabela 5.3. A esse processo atribuímos o nome de alocação tática dos recursos garantidores. É nesse momento que o gestor deve decidir quais ativos dentro de cada segmento interessa aos objetivos do fundo de pensão. Podemos afirmar que a alocação tática complementa o processo de ALM estratégico.

Vamos agora estimar a rentabilidade do fundo de pensão considerando o cenário 29. No problema em tela, o total investido na época 0 é igual a $R \$ 7.812,0$ milhões. Com isso, podemos calcular a taxa interna de retorno considerando como fluxos a despesa previdenciária, a despesa com pagamento de comissões e corretagens e os valores recebidos como contribuição extraordinária subtraídas as devoluções de contribuição feitas aos participantes. O diagrama a seguir representa a situação descrita. 


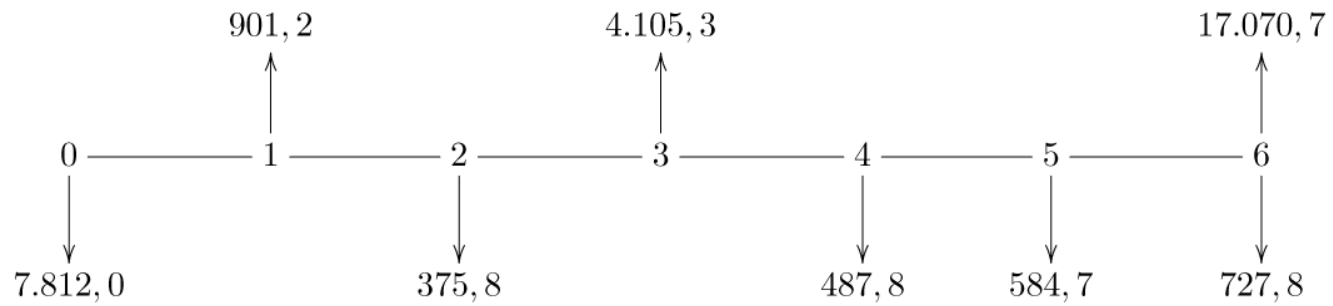

Figura 3: Representação dos fluxos de caixa levando em conta o cenário 29

Feito esse cálculo, obtemos uma taxa interna de retorno igual a 20,18\% ao ano. Se, no mesmo fluxo, forem expurgados os valores das contribuições extraordinárias, a taxa interna de retorno diminui para $9,48 \%$ ao ano. Nesse caso, as entradas de recursos de $R \$ 901,2$ e $R \$ 4.105,3$ milhões, correspondentes a contribuições extraordinárias cobradas de participantes e patrocinadores, deverão ser substituídas por pagamentos de $R \$ 343,20$ e $R \$ 449,4$ milhões, respectivamente.

A Tabela 5.5 exibe o perfil dos investimentos nos seis anos que integram o período de análise. Essa tabela foi obtida dividindo os elementos de cada coluna da Tabela 5.4 pelo total investido no ano considerado. A partir da observação dessa tabela, é possível notar que, no ano 1, o limite máximo de $30 \%$ para aplicação em renda variável foi excedido. Isso se explica uma vez que essa alocação corresponde à alocação inicial, não estando, portanto, sujeita aos limites indicados.

Tabela 5.5: Perfil dos investimentos - cenário 29 expresso em \%

\begin{tabular}{l|r|r|r|r|r|r}
\hline ATIVOS & ANO 1 & ANO 2 & ANO 3 & ANO 4 & ANO 5 & ANO 6 \\
\hline \hline Renda Fixa & 71,11 & 78,92 & 78,09 & 77,24 & 78,84 & 78,00 \\
\hline Renda Variável & 10,86 & 3,00 & 3,00 & 5,31 & 3,00 & 3,00 \\
\hline Imóveis & 10,84 & 11,00 & 11,00 & 11,00 & 11,00 & 11,00 \\
\hline Operações com Participantes & 7,19 & 7,08 & 7,91 & 6,45 & 7,16 & 8,00 \\
\hline \hline $\begin{array}{l}\text { Rentabilidade Estimada } \\
\text { (\% ao ano) }\end{array}$ & 8,68 & 8,14 & 7,41 & 7,84 & 7,23 & 8,24 \\
\hline
\end{tabular}

A última linha da Tabela 5.5 indica as rentabilidades estimadas ao ano levando em conta o perfil dos investimentos e as rentabilidades esperadas, conforme Tabela 5.2. Por fim, mais uma vez, devemos pontuar que o exemplo apresentado foi especialmente preparado para evidenciar uma situação particular 
em que se torna necessário cobrar de participantes e patrocinadores uma contribuição extraordinária $Z_{t}^{s}$. É importante ainda frisar que esse procedimento só deve ser utilizado como recurso extremo, dada a dificuldade que a cobrança de uma contribuição extraordinária representa. No exemplo, procuramos mostrar que outras ações devem ser tentadas antes de decidir pela cobrança dessa contribuição. No próximo exemplo, vamos explorar a situação oposta na qual os participantes terão direito à restituição de contribuição.

\section{2}

\section{Segundo exemplo: Devolução de contribuição}

Nesta seção, analisaremos uma situação em que ocorre um superávit persistente e excessivo. Essa circunstância especial se dá quando a contribuição paga por participantes e patrocinadores é superior àquela necessária para a cobertura dos benefícios prometidos no contrato previdenciário, o retorno real dos investimentos superou a taxa de desconto usada na avaliação atuarial ou ambas as circunstâncias ocorreram simultaneamente. Qualquer que seja a causa desse desequilíbrio, cabe ao gestor do fundo de pensão tomar as decisões para o retorno do equilíbrio atuarial. Dada a relevância do tema, o Conselho de Gestão da Previdência Complementar - CGPC, na resolução 26/08, de 29 de setembro de 2008, dispôs sobre os procedimentos a serem observados pelas entidades fechadas de previdência complementar na destinação e utilização de superávit do plano de benefício.

Art. $8^{\circ}$ Após a constituição da reserva de contingência, no montante integral de $25 \%$ (vinte e cinco por cento) do valor das reservas matemáticas, os recursos excedentes serão empregados na constituição da reserva especial para a revisão do plano de benefícios.

Art. $12^{\circ}$ A revisão do plano de benefícios poderá se dar de forma voluntária, a partir da constituição da reserva especial, e será obrigatória após o decurso de três exercícios.

A resolução CGPC 26 determina, ainda, que superávits superiores a $25 \%$ do valor das reservas matemáticas deverão ser revertidos para a constituição de reserva especial para a revisão do plano de benefícios. Determina também que, 
caso esse superávit seja verificado por prazo superior a três exercícios, o plano de benefícios deverá ser revisto. O Art. $9^{\circ}$ da mesma resolução dá outras indicações:

Art. $9^{\circ} \mathrm{A}$ EFPC, previamente à revisão do plano de benefícios a que se refere o art. $8^{\circ}$, tendo como base parecer atuarial e estudo econômico-financeiro, deverá identificar, mensurar e avaliar a perenidade das causas que deram origem ao superávit.

Parágrafo único. Observado o disposto no caput, a EFPC deverá adotar, além de outras hipóteses consideradas necessárias na avaliação da própria EFPC e do atuário responsável pelo plano:

1. tábua biométrica que gere expectativas de vida completa iguais ou superiores às resultantes da aplicação da tábua AT-2000, observados os itens 2.1 e 2.4 do Regulamento anexo à Resolução no 18, de 28 de março de 2006; e

2. taxa máxima real de juros de $5 \%$ (cinco por cento) ao ano para as projeções atuariais do plano de benefícios.

O procedimento que será abordado neste exemplo diz respeito à utilização de excedentes patrimoniais que serão direcionados para a redução da taxa de desconto atuarial. Vamos considerar que, caso a relação $A_{t}^{S} / L_{t}^{S}$ seja superior a 1,11 por mais de dois períodos consecutivos, o que exceder este valor será utilizado para a redução da taxa de desconto atuarial. Mais uma vez, devemos chamar a atenção para o fato de que o exercício a seguir foi preparado especialmente para evidenciar a contingência anteriormente descrita e não tem o intuito de corresponder a uma situação real.

No exemplo, a contribuição normal paga por participantes e patrocinadores pode variar entre $40 \%$ e $50 \%$ do total da folha de salário dos participantes ativos. Os parâmetros $\alpha$ e $\beta$ foram fixados em 0,95 e 1,11; já $a$ e $b$, em 3 e 2. Isto é, sempre que a relação $A_{t}^{s} / L_{t}^{s}$ for menor do que 0,95 por mais de três anos consecutivos, participantes e patrocinadores deverão um valor $Z_{t}^{s}$ como contribuição extraordinária. Caso $A_{t}^{S} / L_{t}^{s}$ seja maior do que 1,11 por mais de 2 anos consecutivos, os participantes receberão um valor $V_{t}^{S}$. Neste exemplo, foi considerada a árvore binária com a seguinte forma: $[1,2,2,2,2,2]$. Essa árvore se desenvolve em 6 períodos e tem um total de 32 cenários possíveis. Na tabela a seguir, estão sumarizados os valores ótimos de algumas variáveis ou funções destas, determinados no problema de otimização. 
Tabela 5.6: Valores ótimos obtidos considerando o cenário 3

\begin{tabular}{c|c|c|c|c}
\hline $\begin{array}{c}\text { TEMPO } \\
\text { EM ANOS }\end{array}$ & $\begin{array}{c}\text { CONTRIBUIÇÃO } \\
\text { NORMAL INCIDENTE } \\
\text { SOBRE O SALÁRIO }\end{array}$ & $\begin{array}{c}A_{t}^{s} / L_{t}^{s} \\
\text { ANTES DE } Z_{t}^{s}\end{array}$ & $\begin{array}{c}\text { CONTRIBUIÇÃO } \\
\text { A SER DEVOLVIDA } \\
Z_{t}^{s} \text { EM } R \$ \text { MIL }\end{array}$ & $\begin{array}{c}A_{t}^{s} / L_{t}^{s} \\
\text { DEPOIS DE } Z_{t}^{s}\end{array}$ \\
\hline \hline 1 & $40,00 \%$ & 1,1100 & - & 1,1000 \\
\hline 2 & $40,00 \%$ & 1,1072 & - & 1,1072 \\
\hline 3 & $40,00 \%$ & 1,1408 & - & 1,1408 \\
\hline 4 & $40,00 \%$ & 1,1179 & 77,6 & 1,1000 \\
\hline 5 & $40,00 \%$ & 1,1581 & 507,9 & 1,1000 \\
\hline 6 & $40,00 \%$ & 1,2052 & $1.078,1$ & 1,1000 \\
\hline \hline
\end{tabular}

Na Tabela 5.6, é possível observar que, nos anos 3, 4, 5 e 6, o total do ativo dos participantes excedeu em mais de $11 \%$ as provisões matemáticas por mais de dois anos consecutivos. Nesse caso, o valor $V_{t}^{s}$ do excesso deverá ser devolvido aos participantes. Vamos, no entanto, constituir um fundo financeiro que permita reduzir a taxa de desconto atuarial. Dada a relação funcional entre taxa de desconto atuarial e provisões matemáticas, quando essa taxa é reduzida ocorre um aumento nas provisões matemáticas. Vamos supor que a redução de $1 \%$ na taxa de desconto atuarial implique uma elevação de $16 \%$ no passivo atuarial do fundo. Nesse caso, ao final do sexto ano, considerando o cenário de número 3, o fundo de pensão terá acumulado recursos suficientes para suportar uma redução na taxa de desconto atuarial de, aproximadamente $0,9 \%$ do passivo atuarial. Desse modo, o fundo de pensão objeto deste exemplo poderá reduzir sua taxa de desconto atuarial para valores próximos a 5\% ao ano. Independentemente dos valores numéricos envolvidos neste exemplo, o fato mais importante a ser destacado é a regra implícita que consiste em permitir que seu compromisso passe a ser reduzi-la sempre que o desempenho financeiro-atuarial do fundo permitir. Essa estratégia privilegia a geração frequente de resultados e não a geração de um resultado significativo. Então, a regra a ser estabelecida deve indicar que, sempre que a relação $A_{t}^{s} / L_{t}^{s}$ for superior a um valor previamente indicado por mais de $b$ anos consecutivos (no caso em apreço, esses parâmetros foram fixados em 1,11 e 2), o gestor deve constituir um fundo financeiro para recolher esse excesso. Os recursos coletados nesse fundo serão utilizados para a redução da taxa de desconto atuarial. Essa regra permite que os recursos excedentes gerados pelo fundo de 
pensão sejam utilizados para adequar as hipóteses atuariais, reduzindo assim o risco de desequilíbrio ou de insolvência do fundo de pensão.

$\mathrm{Na}$ tabela a seguir, vamos mostrar as rentabilidades dos ativos que compõem os segmentos usados neste segundo exemplo. Correndo o risco da repetição, é importante ressaltar que os valores considerados neste exercício podem não corresponder a um cenário com grande probabilidade de ocorrência. Este é apenas um exercício numérico cujo principal objetivo é apresentar as possibilidades de gestão de um fundo de pensão ante questões relevantes.

Tabela 5.7: Retorno dos ativos - cenário 3 expresso em \% ao ano

\begin{tabular}{l|r|r|r|r|r|r}
\hline ATIVOS & ANO 1 & ANO 2 & ANO 3 & ANO 4 & ANO 5 & ANO 6 \\
\hline \hline Renda Fixa & 12,00 & 11,76 & 11,33 & 11,40 & 11,62 & 12,48 \\
\hline Renda Variável & 8,56 & 3,41 & 1,45 & 17,74 & 8,66 & 48,85 \\
\hline Imóveis & 11,83 & 12,34 & 9,67 & 9,66 & 8,83 & 9,38 \\
\hline Operações com Participantes & 9,70 & 10,20 & 7,58 & 7,56 & 6,76 & 7,30 \\
\hline \hline
\end{tabular}

Os recursos financeiros serão alocados em função das rentabilidades esperadas em cada segmento permitido (conforme explicitado na Tabela 5.7), das restrições impostas no problema e da necessidade de pagar os benefícios indicados no contrato previdenciário. Compras e vendas de ativos estão ainda restritas aos seus limites inferiores e superiores. No exemplo em estudo, foram admitidos os seguintes limites superiores para a alocação de recursos: renda fixa, 100\%; renda variável, $50 \%$; imóveis, $11 \%$; e operações com participantes, $8 \%$. Os limites inferiores para aplicação de recursos foram todos fixados em 0 , exceto o limite do ativo renda variável, para o qual foi estabelecido um limite de $3 \%$.

A tabela a seguir mostra o total das compras e das vendas efetuadas, considerado o cenário 3. Na tabela, os valores grafados em vermelho indicam vendas efetuadas. 
Tabela 5.8: Compras e vendas de ativos - cenário 3 expresso em milhões de Reais

\begin{tabular}{l|r|r|r|r|r}
\hline ATIVOS & \multicolumn{1}{|c|}{ ANO 1 } & \multicolumn{1}{c|}{ ANO 2 } & \multicolumn{1}{c|}{ ANO 3 } & \multicolumn{1}{c|}{ ANO 4 } & \multicolumn{1}{c}{ ANO 5 } \\
\hline \hline Renda Fixa & 217,0 & 0,0 & 293,9 & $1.978,5$ & $1.987,5$ \\
\hline Renda Variável & 174,8 & 497,3 & 181,9 & $2.061,4$ & $2.349,5$ \\
\hline Imóveis & 283,8 & 639,3 & 43,0 & 22,9 & 0,0 \\
\hline Operações com Participantes & 0,0 & 0,0 & 0,0 & 0,0 & 0,0 \\
\hline \hline Saldo das Operações & 108,0 & 142,0 & 155,0 & 60,0 & 362,0 \\
\hline
\end{tabular}

Uma característica do modelo utilizado neste trabalho é que os recursos gerados pela atividade de investimento são necessários para alguma finalidade específica. Em especial, os recursos coletados (fontes) serão utilizados (usos) para o pagamento dos benefícios devidos aos assistidos, para a cobertura de todas as despesas com a operação do fundo de pensão, para a compra de ativos e para a eventual devolução de contribuição aos participantes e assistidos. Além das receitas e despesas que figuram nas diversas tabelas apresentadas ao longo do texto, serão incluídas as despesas com o pagamento de corretagens nas operações de compra e venda de ativos. Neste trabalho, compras e vendas são oneradas pelo pagamento de $1 \%$ do valor da operação a título de corretagem. Representamos as fontes e usos dos recursos gerados na tabela a seguir.

Tabela 5.9: Fontes e usos de recursos - cenário 3 expressos em milhões de Reais

\begin{tabular}{l|r|r|r|r|r}
\hline & ANO 1 & ANO 2 & ANO 3 & ANO 4 & \multicolumn{1}{c}{ ANO 5 } \\
\hline \hline Recursos Coletados & $\mathbf{2 . 1 5 3 , 0}$ & $\mathbf{1 . 1 7 4 , 0}$ & $\mathbf{1 6 . 8 1 9 , 0}$ & $\mathbf{2 . 7 8 5 , 0}$ & $\mathbf{3 . 1 8 5 , 0}$ \\
\hline \hline Contribuição Normal & 614,0 & 677,0 & 728,0 & 783,0 & 836,0 \\
\hline Contribuição Extraordinária $-Z_{t}^{s}$ & 0,0 & 0,0 & 0,0 & 0,0 & 0,0 \\
\hline Venda de Ativos & $1.539,0$ & 497,0 & $16.091,0$ & $2.001,0$ & $2.349,0$ \\
\hline \hline Uso dos Recursos & $\mathbf{2 . 1 5 3 , 0}$ & $\mathbf{1 . 1 7 4 , 0}$ & $\mathbf{1 6 . 8 1 9 , 0}$ & $\mathbf{2 . 7 8 5 , 0}$ & $\mathbf{3 . 1 8 5 , 0}$ \\
\hline \hline Devolução de Contribuição $-V_{t}^{s}$ & 0,0 & 0,0 & 0,0 & 77,6 & 507,9 \\
\hline Pagamento de Benefícios & 475,0 & 523,0 & 563,0 & 606,0 & 647,1 \\
\hline Compra de Ativos & $1.647,0$ & 639,0 & $15.936,0$ & $2.061,0$ & $1.987,0$ \\
\hline Pagamento de Corretagens & 32,0 & 11,0 & 320,0 & 41,0 & 43,0 \\
\hline
\end{tabular}

O fundo de pensão caracterizado nesse exemplo apresenta despesa previdenciária inferior à receita previdenciária. Nesse caso, diz-se que o fundo de pensão ainda não atingiu a maturidade. Essa diferença positiva será usada para a aquisição de ativos financeiros. 
A Tabela 5.9 exibe o Demonstrativo de Fluxo de Caixa. Esse é um valioso demonstrativo que permite a identificação dos recursos livres, que constituem a base para a determinação da taxa interna de retorno - importante medida para avaliar o desempenho financeiro do fundo de pensão.

Tabela 5.10: Demonstrativo de fluxo de caixa - cenário 3 expressos em milhões de Reais

\begin{tabular}{l|r|r|r|r|r|r}
\hline FLUXOS & ANO 1 & ANO 2 & ANO 3 & ANO 4 & ANO 5 & ANO 6 \\
\hline \hline$(+)$ Contribuição Normal & 614,0 & 677,0 & 728,0 & 783,0 & 836,0 & 897,3 \\
\hline$(+)$ Contribuição Extraordinária - $Z_{t}^{s}$ & 0,0 & 0,0 & 0,0 & 0,0 & 0,0 & 0,0 \\
\hline$(-)$ Devolução de Contribuição $-V_{t}^{s}$ & 0,0 & 0,0 & 0,0 & 77,6 & 507,9 & $1.078,1$ \\
\hline$(-)$ Benefícios Pagos & 475,0 & 523,0 & 563,0 & 606,0 & 647,1 & 693,8 \\
\hline$(-)$ Corretagens Pagas & 32,0 & 11,0 & 320,0 & 41,0 & 43,0 & 0,0 \\
\hline$(+/-)$ Ajuste & 1,0 & 1,0 & 0,0 & 1,6 & 0,0 & 0,0 \\
\hline \hline Fluxo de Caixa Livre & $\mathbf{1 0 8 , 0}$ & $\mathbf{1 4 2 , 0}$ & $\mathbf{1 5 5 , 0}$ & $\mathbf{6 0 , 0}$ & 362,0 & $\mathbf{8 7 4 , 6}$ \\
\hline
\end{tabular}

Até o momento já foram exibidas as rentabilidades dos ativos, as compras e as vendas realizadas. Adicionalmente, foram apresentados o demonstrativo de usos e fontes e o demonstrativo de fluxo de caixa. Uma vez conhecidas as rentabilidades esperadas dos ativos, indicadas na Tabela 5.2, e a política de compras e vendas de ativos, descritas na Tabela 5.3, podemos indicar a distribuição dos ativos ao longo dos anos que compõem o horizonte de planejamento. O total desses investimentos, que é função das rentabilidades dos ativos (conforme indicado na Tabela 5.7) e das restrições impostas ao modelo, é apresentado na tabela a seguir. Os elementos da Tabela 5.8 e da Tabela 5.9 representam a base para a alocação tática dos recursos garantidores das provisões matemáticas.

Tabela 5.11: Total investido - cenário 3 expresso em milhões de Reais

\begin{tabular}{l|r|r|r|r|r|r}
\hline ATIVOS & \multicolumn{1}{c|}{ ANO 1 } & \multicolumn{1}{c|}{ ANO 2 } & \multicolumn{1}{c|}{ ANO 3 } & \multicolumn{1}{c|}{ ANO 4 } & \multicolumn{1}{c|}{ ANO 5 } & \multicolumn{1}{c}{ ANO 6 } \\
\hline \hline Renda Fixa & $4.955,0$ & $5.766,6$ & $6.444,7$ & $6.881,1$ & $5.687,1$ & $8.335,5$ \\
\hline Renda Variável & $1.735,5$ & $1.761,8$ & $1.204,5$ & $1.369,0$ & $3.186,9$ & $1.113,8$ \\
\hline $\begin{array}{l}\text { Imóveis } \\
\begin{array}{l}\text { Operações com } \\
\text { Participantes }\end{array}\end{array}$ & 572,1 & 355,4 & $1.038,8$ & $1.096,2$ & $1.179,1$ & $1.283,2$ \\
\hline \hline Total Investido & $7.888,6$ & 685,5 & 755,5 & 812,7 & 874,2 & 933,3 \\
\hline
\end{tabular}


A Tabela 5.11 representa o ideal a ser buscado pelo gestor dos investimentos no fundo de pensão. É importante frisar que o modelo matemático que permite construir essa tabela não é (ao menos não diretamente) um modelo de maximização do retorno do fundo de pensão. Na verdade, a Tabela 5.11 serve apenas como um guia para a alocação dos recursos garantidores nos segmentos permitidos pela legislação.

Neste trabalho, abordamos o que se convencionou chamar de ALM estratégico. Nessa abordagem não existe preocupação com a alocação de recursos nas carteiras que compõem os diversos segmentos. Este justo interesse fica sob a responsabilidade do profissional encarregado da microalocação dos ativos. Esse profissional, a partir da determinação das compras e vendas efetuadas em cada segmento, deverá tomar as decisões sobre os ativos a serem transacionados e as condições que essas transações devem obedecer. No ALM tático, o modelo de otimização já inclui, além dos segmentos permitidos, os diversos ativos de cada segmento. Neste trabalho, fizemos uma opção conceitual pela utilização da estrutura do modelo ALM estratégico. Em nosso julgamento, a determinação da microalocação de recursos pode ser implementada por meio de ferramentas específicas.

Neste ponto, já reunimos as condições necessárias para determinar a rentabilidade da estratégia indicada, medida pela taxa interna de retorno. Para tal, vamos fazer uso das informações contidas na Tabela 5.10 e na Tabela 5.11. No problema considerado, o total investido na época 0 é igual a $R \$ 7.812,0$ milhões, devendo ser este o valor inicial do total do ativo dos participantes. Os demais elementos estão indicados no diagrama a seguir.

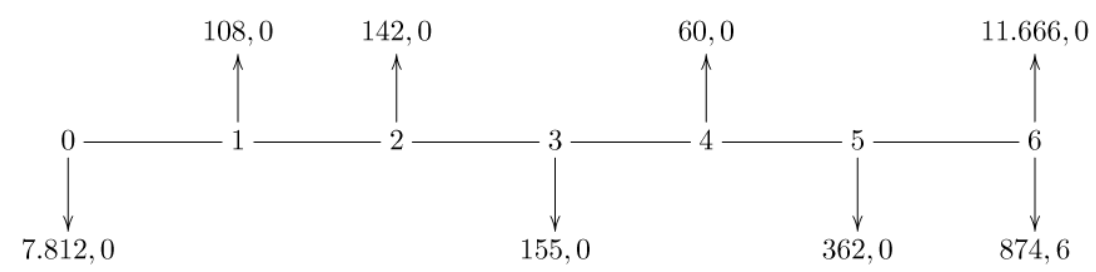

Figura 4: Representação dos fluxos de caixa levando em conta o cenário 3

A taxa interna de retorno do fluxo de caixa é igual a 5,2\% ao ano. Essa rentabilidade mede o desempenho dos investimentos levando em conta a devolução de contribuição efetuada nos $\operatorname{anos} 4,5$ e 6 . Caso esses valores não 
houvessem sido devolvidos aos participantes, a rentabilidade, medida pela taxa interna de retorno, teria sido de 7,9\% ao ano.

A Tabela 5.12, a seguir, exibe o perfil dos investimentos nos seis anos que integram o período de análise. Essa representação é bastante útil uma vez que permite ao gestor verificar um possível desenquadramento em limites preestabelecidos. Ainda sobre a Tabela 5.12, é possível observar que incluímos um item denominado Rentabilidade Estimada na última linha. Essa é uma estimativa da rentabilidade das aplicações de recursos em cada ano. Tal estimativa foi obtida considerando os valores contidos na Tabela 5.7 e na Tabela 5.12.

Tabela 5.12: Perfil dos investimentos - cenário 3 expresso em \%

\begin{tabular}{c|c|c|c|c|c|c}
\hline ATIVOS & ANO 1 & ANO 2 & ANO 3 & ANO 4 & ANO 5 & ANO 6 \\
\hline Renda Fixa & 62,83 & 67,29 & 68,25 & 67,73 & 52,05 & 71,45 \\
\hline Renda Variável & 22,00 & 20,56 & 12,75 & 13,48 & 29,16 & 9,55 \\
\hline Imóveis & 7,25 & 4,15 & 11,00 & 10,79 & 10,79 & 11,00 \\
\hline \hline \begin{tabular}{c} 
Operações com Participantes \\
\hline $\begin{array}{c}\text { Rentabilidade Estimada } \\
\text { (\% ao ano) }\end{array}$
\end{tabular} & 7,92 & 8,00 & 8,00 & 8,00 & 8,00 & 8,00 \\
\hline
\end{tabular}

Essa tabela encerra o segundo exemplo que desejávamos explorar. Cada um deles exibiu uma característica relevante na modelagem abordada nesta dissertação. Em comum, os dois apresentam situações limites da taxa de contribuição. No primeiro, focamos a necessidade de cobrar uma contribuição extraordinária de participantes e patrocinadores; já no segundo, forçamos a situação em que parte da contribuição excessiva deveria ser devolvida aos participantes. Nas duas circunstâncias, o modelo matemático sugere um comportamento que deve ser discutido entre as partes envolvidas para que os gestores do fundo de pensão determinem uma decisão tática de investimentos plurianuais. Em ambos os exemplos, consideramos um horizonte de planejamento de seis anos. É válido supor que, neste período, os cenários considerados podem sofrer profundas modificações. Nesse caso, o gestor deve ser suficientemente hábil para, tempestivamente, alterar as determinações de investimentos a fim de acompanhar, o mais próximo possível, o cenário que se configura. Como a base de decisão é anual, a cada ano devemos processar o modelo em questão para obter 
novas indicações de investimentos a partir da realidade observada naquele momento. Esse exercício de reprocessamentos sucessivos deverá, por fim, criar uma disciplina na qual os gestores e modelo serão aliados, cada um deles respeitando os claros limites de alcance do outro. 


\section{Conclusões}

Neste trabalho, abordamos a gestão de um fundo de pensão do tipo benefício definido a partir de uma estratégia concebida por iniciativa de um colegiado superior. Procuramos deixar claro, durante todo o desenvolvimento, a relação de causa e efeito entre ativo e passivo. Essa relação é levada ao extremo seguindo o conceito de que as ações sobre os investimentos são ultimadas não apenas levando em conta a necessidade de pagar os benefícios garantidos no contrato previdenciário, mas também, e principalmente, pela necessidade de preservar a liquidez e equilíbrio atuarial em todos os anos do horizonte de planejamento. O problema de ALM considerado neste trabalho é de classe estratégica, no qual não importa o tipo específico do ativo, apenas a classe a que pertence. Nesse sentido, para complementar os resultados indicados pela metodologia desenvolvida, são necessárias ferramentas analíticas que permitam transformar indicações genéricas de como transacionar ativos de um segmento em decisões específicas de como transacionar ativos do segmento recomendado.

O problema resolvido faz uso de programação inteira com o objetivo de contar o número de ocorrências de um determinado evento. Essa escolha, apesar dos problemas computacionais que suscita, torna o problema mais realista e totalmente aderente à legislação aplicável ao abordar como déficits e superávits devem ser tratados pelos fundos de pensão. Todo o problema é desenvolvido considerada a capacidade do usuário de elaborar cenários que, além de satisfazerem um arranjo numérico específico, devem também obedecer a relações econométricas conhecidas. Nesse ponto, encontramos uma grande dificuldade pela inexistência de informações de abrangência adequada, que permitam uma estimação estatisticamente consistente. Essa vulnerabilidade implica um esforço adicional fora do escopo deste trabalho.

Outra questão cuja abordagem utilizada pode e deve ser melhorada é a geração dos fluxos do passivo atuarial e, consequentemente, dos fluxos de benefícios pagos aos assistidos. Nesta dissertação, esses fluxos foram estimados considerando que o passivo dos participantes evolui ritmado pela evolução geral 
dos salários praticados pelo patrocinador. Como extensão deste trabalho, temos algumas proposições, descritas a seguir.

1. Cenários: Usar metodologia estatística que permita fazer previsões conjuntas das variáveis relevantes para o modelo que, mesmo levando em conta a escassez de informações disponíveis, permita estimar consistentemente as variáveis necessárias para o horizonte de planejamento considerado.

2. Passivo Atuarial: O próximo objetivo é transformar o modelo de ALM determinístico em estocástico. Para isso, é necessário desenvolver um modelo de avaliação atuarial estocástica. Esse procedimento, além de fornecer ao atuário e demais gestores do fundo de pensão toda a riqueza ensejada pelos métodos estocásticos, permitirá igualmente robustecer o problema de ALM pela natural possibilidade de gerar medidas estatísticas sobre as diversas variáveis de decisão.

3. Risco: A concepção atual de gestão de negócios exige cada vez mais dos gestores a estimação dos riscos ao qual está submetido e, principalmente, como decorrência dessa capacidade de avaliação, a elaboração de ações mitigadoras dos riscos identificados. No futuro, nosso objetivo é introduzir um conjunto de medidas de risco que permitam ao gestor um conhecimento melhor dos riscos a que o negócio fundo de pensão está exposto. 


\section{Referências bibliográficas}

[1] Fourer, Robert, Gay, David, M. and Kernighan, Brian, W. AMPL: A Modeling for Mathematical Programming. Second Edition, 2002.

[2] SOA - Society of Actuaries www.soa.org/

[3] Macaulay, Frederick R., The Movements of Interest Rates. Bond Yields and Stock Prices in the United States since 1856, New York: National Bureau of Economic Research 1938.

[4] James, Jessica and Webber, Nick. Interest Rate Modelling. Wiley series in financial engineering, 2000.

[5] Fabozzzi, Frank J. Mercado, Análise e Estratégias de Bônus. Qualitymark, 2000 .

[6] Feldblun, Shalom. Asset Liability Maching for Property/Casualty Insurers, CPCU journal, p. 117-154, 1998.

[7] Li, Duan and Ng, Wan-Lung Optimal Dynamic Portfolio Selection: Multiperiod Mean-Variance Formulation. Mathematical Finance, Vol. 10, No. 3. (July 2002), pp. 387-406.

[8] Prajogi, Robertus; Muralidhar, Arun e van der Wouden, Ronald J.P., An Asset-Liability Analysis of the Currency Decision for Pension Portfolios. Derivatives Quarterly Winter 2000 v7 i2 p47 Page 1.

[9] David R. Carino e William T. Ziemba Formulation of the Russel - Yasuda Kasai Financial Planning Model. Operations Research, Vol. 46, No. 4. (Jul. - Aug., 1998), pp. 433-449.

[10] David R. Carino; David H. Myers; William T. Ziemba. Concepts, Technical Issues, and Uses of the Russell-Yasuda Kasai Financial Planning Model, Operations Research, Vol. 46, No. 4. (Jul. - Aug., 1998), pp. 450-462.

[11] Roy Kouwenberg Scenario generation and stochastic programming models for asset liability management, Erasmus University Rotterdam.

[12] Kall, Peter e Mayer, János, Stochastic Linear Programming Models, Theory, and Computation. Springer, 2005.

[13] C.L. Dert. Asset Liability Management for Pension Funds., A Multistage Chance Constrained Programming Approach. $\mathrm{PhD}$ thesis, Erasmus University, Rotterdam, The Netherlands, 1995.

[14] Birge, John, R. e Louveaus, Fraçois, Introduction to Stochastic Programming. Springer Series in Operations Research, 1997. 
[15] Willem K. Klein Haneveld e Maarten H. van der Vlerk. $h_{i}$ Vank. Integrated chance constraints: reduced forms and an algorithm. http://som.rug.nl, 2002.

[16] Willem K. Klein Haneveld, Matthijs H. Streutker e Maarten H. van der Vlerk. An ALM Model for Pension Funds using Integrated Chance Constraints. Department of Econometrics \& OR University of Groningen, 2005.

[17] Drijver, Sibrand J. ; Haneveld, Willem K. Klein e Van der Vlerk, Maarten H., Asset Liability Management modeling using multi-stage mixed-integer Stochastic Programming September 2000.

[18] Hull, John C., Options, Futures, and Other Derivative Securities PrenticeHall, Inc. second edition 1993.

[19] Glasserman, Paul. Monte Cario Methods in Financial Engineering. Springer, 2004.

[20] Arjen H. Siegmann e Lucas, André, Continuos-Time Dynamics Programming for ALM Whith Risk Averse Loss Functions, Vrije Universiteit/Tinbergen Institute Keizersgracht 482, 1017 EG Amsterdam, The Netherlands.

[21] Øksendal, B., Stochastic Differential Equations: An introduction with applications, Spring-Verlag, 5th edition, 1998.

[22] Korn, Ralf and Korn, Elke. Option Pricing and Portfolio Optimization: Modern Methods of Financial Mathematics (Graduate Studies in Mathematics) American Society, 2001.

[23] James, Barry R., Probabilidade: Um curso em nível intermediário. Editora: LTC, 2ed, 1996.

[24] Pliska, Stanley, R., Introduction to Mathematical Finance. Blackwell Publishers Inc, 1999.

[25] Xiaodong Ji, Shushang Zhu, Shuzhong Zhang. A stochastic linear goal programming approach to multistage portfolio management based on scenario generation via linear programming.

[26] Mulvey, John M, Multi-stage Optimization for Long-term Investors. http://www.princeton.edu/ bcf, September 2000. 